\title{
When does lexical availability influence phonology? Evidence from jargon reading and repetition
}

Article

Accepted Version

Pilkington, E., Sage, K., Saddy, D. and Robson, H. (2020) When does lexical availability influence phonology? Evidence from jargon reading and repetition. Language, Cognition and Neuroscience, 35 (4). pp. 521-540. ISSN 2327-3801 doi: https://doi.org/10.1080/23273798.2019.1676456 Available at https://centaur.reading.ac.uk/86235/

It is advisable to refer to the publisher's version if you intend to cite from the work. See Guidance on citing.

To link to this article DOI: http://dx.doi.org/10.1080/23273798.2019.1676456

Publisher: Taylor \& Francis

All outputs in CentAUR are protected by Intellectual Property Rights law, including copyright law. Copyright and IPR is retained by the creators or other copyright holders. Terms and conditions for use of this material are defined in the End User Agreement.

www.reading.ac.uk/centaur 
Central Archive at the University of Reading

Reading's research outputs online 


\title{
When does lexical availability influence phonology? Evidence from Jargon reading and repetition.
}

\author{
Emma Pilkington ${ }^{a^{*}}$, Karen Sage ${ }^{\mathrm{b}}$, Douglas Saddya , and Holly Robson ${ }^{\mathrm{a}}$
}

aSchool of Psychology and Clinical Language Sciences, University of Reading, Reading, UK. ${ }^{b}$ Department of Allied Health Professions, Sheffield Hallam University, Sheffield, UK. *School of Psychology and Clinical Language Sciences, University of Reading, Reading, UK, RG67BE.E.c.pilkington@pgr.reading.ac.uk

\section{Authorship statement}

E. Pilkington: conceptualisation; methodology; resources (recruitment and data collection), curation and analysis; manuscript preparation; visualisation; funding acquisition.

K. Sage: conceptualisation; methodology; manuscript review and editing; supervision; funding acquisition.

D. Saddy: conceptualisation; methodology; manuscript review and editing; supervision; funding acquisition.

H. Robson: conceptualisation; methodology; resources (participant recruitment); manuscript review and editing; supervision; funding acquisition. 


\subsection{Abstract}

Jargon aphasia is a language disorder characterised by phonological and nonword error. Errors are thought to arise when target segments are insufficiently activated, allowing non-target or recently used phonology to intrude. Words which are more frequent and familiar reside with greater degrees of activation and therefore should be less susceptible to error. The current study tested this hypothesis in a group of ten people with Jargon aphasia using single word repetition and reading aloud. Each task had two lexicality conditions, one high and one low lexical availability word set. Measures of nonword quantity, phonological accuracy and perseveration were used in group and case series analyses. Results demonstrated that fewer nonwords were produced when lexical availability was greater. However, lexicality effects on phonological accuracy and perseveration were only observed in repetition in a sub-group of moderately impaired individuals, demonstrating that lexical information does not consistently influence phonological processing in Jargon aphasia. 


\subsection{Introduction}

\subsubsection{Jargon aphasia production}

Jargon aphasia is a form of acquired language impairment characterised by nonsensical spoken production post brain damage (Blumstein, Cooper, Goodglass, Statlender, \& Gottlieb, 1980; Hillis, 2007). The semantic form of Jargon aphasia is associated with production of real word errors which are often semantically unrelated to the context or target word. Such errors are thought to occur secondary to lexico-semantic impairment, impacting word selection and rendering production incomprehensible (Brown, 1981; Marshall, Chiat, Robson \& Pring, 1996; Marshall, Pring, Chiat \& Robson, 1996). This contrasts with the phonological form of Jargon aphasia which is characterised by nonword error production. This study is concerned with phonological Jargon aphasia (referred to as Jargon aphasia from hereafter). Nonword errors occur when phonological segment errors contaminate a word, for example, the word 'winter' read aloud as /winstə/. The degree of phonological segment error within nonwords is variable and can affect all or most of the phonemes within a word, for example, the word 'ocean' being read aloud as /senivit J/. The phonological accuracy within nonwords is thought to vary with the amount of lexico-phonological constraint, with errors such as /senivit / arising from significant lexico-phonological disruption and nonwords such as /winstə/ occurring with much milder disruption to segment selection (Marshall, 2006; Olson, Romani and Halloran, 2015; Schwartz, Wilshire, Gagnon and Polansky, 2004). Attempts to elicit nonword production errors from healthy controls succeed in generating slip-of-the tongue like error, but the severity and quantity observed in Jargon aphasia is unmatched (Baars, Motley \& MacKay, 1975; Dell \& Reich, 1981; Schwartz, Saffran, Bloch \& Dell, 1994).

In Jargon aphasia nonwords occur in abundance. However, as people produce Jargon, they often make little or no effort to correct their erroneous production (Alajouanine, 1956; Kertesz \& Benson, 1970). This pattern of production has been partly linked to impaired self-awareness and reduced monitoring of self-generated speech. Kinsbourne and Warrington (1963) report two individuals with copious errorful speech output who, when asked, stated no awareness of their Jargon impairment. Marshall, Robson, Pring and Chiat (1998) document that RMM, a lady with severe Jargon production, spoke fluently and produced highly errorful and incomprehensible speech, yet made 
little attempt to self-correct. People with Jargon aphasia often present with impairments in auditory processing and comprehension, which have been linked in some cases to the impaired ability to monitor and detect errors in production (Purcell, Lambon-Ralph, \& Sage, 2018; Sampson \& Faroqi-Shah, 2011). This is consistent with the lesion profile in Jargon aphasia, which commonly includes the primary and secondary auditory cortices of the left superior temporal gyrus (Kertesz \& Benson, 1970; Pilkington et al., 2017) which are involved in acoustic analysis and the extraction of phonetic and phonological information (Mesgarani, Cheung, Johnson, \& Chang, 2014). Many individuals with Jargon aphasia present with a wider language profile of Wernicke's aphasia, a condition associated with a similar lesion profile (Robson, Specht, Beaumont, Parkes, Sage, Lambon Ralph \& Zahn, 2017), and established auditory processing impairment (Robson, Grube, Lambon Ralph, Griffiths \& Sage, 2013). However, a number of Jargon case reports identify people with relatively persevered auditory processing ability alongside persistent failure to monitor or inhibit their own errors (Kohn, Smith \& Alexander, 1996; Marshall et al., 1998; Olson et al., 2015; Robinson, Butterworth, \& Cipolotti, 2015) and, therefore, auditory processing impairments do not appear to be a necessary feature of Jargon aphasia.

In addition to auditory processing and perception regions, lesion profiles - commonly involving the left posterior superior temporal gyrus and supramarginal gyrus - also implicate retrieval of phonological sequences and word forms (Binder, 2017; Buchsbaum et al., 2011; Hillis, Boatman, Hart, \& Gordon, 1999; Kertesz, 1981; Kertesz \& Benson, 1970; Pilkington et al., 2017). Behavioural data align with the lesion profile, in that error production patterns indicate a strong role of phonological processing in nonword generation. Analyses of nonword phonology demonstrate that both high and low accuracy nonwords reflect the correctly selected word representation which is disrupted during phonological segment processing, indicated by greater than chance phonological accuracy (Buckingham \& Kertesz, 1974; Kohn, Smith, \& Alexander, 1996; Olson, Halloran, \& Romani, 2015; Olson, Romani, \& Halloran, 2007; Pilkington et al., 2017; Robson, Pring, Marshall, \& Chiat, 2003). Perseveration - the repeated use of error phonemes across consecutive responses - is also frequently observed in Jargon aphasia and usually affects phonological segment production. 
The patterns of perseveration observed in Jargon aphasia suggest that target words and/or phonology are insufficiently activated because parts of the language network are damaged, and this damage impedes activation flow within the network and compromises production. This is referred to as the activation deficit account, and by this theory damage affecting word selection processes will generate word perseverations whereas damage to phonological representations will more likely generate phoneme perseverations (Moses, Sheard \& Nickels, 2007; Stark, 2007). In Jargon aphasia, which is associated with phonological impairment, weakly activated phonological segments will be less able to override residual activation at previously used segments and a phonological perseveration will be produced (Martin and Dell, 2007; Hirsh, 1998). Interactive two-step models of lexical processing have evaluated this activation deficit account in large groups of people who produce nonword errors, demonstrating that insufficiently activated target phonological segments underpin nonword production and can arise as a consequence of insufficient semantic-conceptual, lexical or phonological activation (Dell, Schwartz, Martin, Saffran, \& Gagnon, 1997; Foygel \& Dell, 2000; Martin \& Dell, 2007). Intrinsic noise or residual activation at recently used segments, if greater than the impoverished target activation, will override target segments and prevail for production (Cohen \& Dehaene, 1998; Dell, Martin, \& Schwartz, 2007; Dell, Schwartz, Martin, Saffran, \& Gagnon, 1997; Martin \& Dell, 2007; Moses, Nickels, \& Sheard, 2004; O'Connell, 1981). Decreasing the amount of semantic or word level activation in computational models generates greater numbers of nonword and perseverative errors and the generated error patterns conform to data observed in large groups of people with aphasia, including people who perseverate (Dell, Martin, \& Schwartz, 2007; Martin \& Dell, 2007), suggesting that lexico-semantic activation influences phonological processing and nonword error production in people with aphasia. Perseveration occurs in greater amounts on tasks of single word production (Buckingham, 1990; Buckingham \& Buckingham, 2011) and is more common in individuals who present with more severe production impairments. However, not all persons with Jargon aphasia exhibit perseveration (Pilkington et al., 2017). Kohn, Smith and Alexander (1996) propose that perseveration is a diagnostic indicator of the underlying deficit, suggesting that perseveration occurs when lexical-phonological representations have been damaged or lost such that activation cannot transfer within the lexical network, meaning processing is based primairly on prior production. On the 
contrary, Kohn, Smith and Alexander (1996) suggest that people who have impaired access to presevered representations are unlikely to perseverate because they can make use of alternate, neighnouring respresentations to support production. There are few studies exmaining such patterns in Jargon aphasia, and more work explroing perseveration is important to better understand the Jargon impairment. There are few studies examining such patterns in Jargon aphasia and more work exploring perseveration is required to better understand the underlying mechanisms. Perseveration is also observed in other neurological conditions including Parkinson's disease, dementia and other stroke profiles and is often associated with frontal lobe disturbance or sub-cortical damage involving the basal ganglia or the thalamus (Bayles, Tomoeda, Kaszniak, Stern \& Eagans, 1985; Pekkala, Albert, Spiro, \& Erkinjuntti, 2008; Robin \& Schienberg, 1990; Sandson \& Albert, 1984; 1987). Perseveration in these conditions has been associated with a range of executive functioning impairments including failed inhibition of a previous response or a thought process, impaired attention, and working memory deficits (Fischer-Baum \& Rapp, 2012; Frankell, Penn, \& Ormond-Brown, 2010; Papagno \& Basso, 1996; Purcell et al., 2018; Robinson, et al., 2015; Santo-Pietro \& Rigrodsky, 1980; Yamadori, 1981). The extent to which these factors influence the Jargon aphasia impairment is yet to be established.

The Jargon aphasia label is not a traditional subtype of aphasia and is not found within diagnostic assessment batteries, therefore, identifying Jargon aphasia is not straightforward. Traditional accounts of Jargon aphasia describe nonword error patterns within connected speech samples (Buckingham, 1977; Buckingham \& Kertesz, 1974; Kertesz \& Benson, 1970; Kinsbourne \& Warrington, 1963), and thus, application of the Jargon aphasia label has typically been adopted when reporting individuals who produce high proportions of nonword error within connected speech (Brown, 1981; Marshall, 2006). However, the most consistent diagnostic feature reported in Jargon aphasia studies is high numbers of nonword error production (Bose, 2013; Eaton, Marshall \& Pring, 2011; Kohn, Smith \& Alexander, 1996; Marshall et al., 1998; Olson, et al., 2015). Single word production tasks are an ideal way to study nonwords because the target-nonword relationship is overt. For example, the nonword response /senivit f/ would be difficult to relate back to its source word, 'ocean' if produced in a connected speech task where the target word ocean was not known to the experimenter. Single 
word production tasks circumvent this challenge as the target word is pre-defined, which allows for close examination of accuracy at the phonological level. Many existing studies make use of the advantages offered from a single word production paradigm, using picture naming, reading and repetition as probes of nonword production (Bose, 2013; Kohn et al., 1996; Martin \& Dell, 2007; Pilkington et al., 2019; Olson et al., 2015; Schwartz et al., 1994; 2004). Repetition and reading offer an advantage over picture naming in that they allow for more flexible manipulation of semantic word properties such as imageability and are not confounded by name agreement.

\subsubsection{Lexical influences in reading and repetition}

The influence of word level activation over phonological processing has been widely explored in numerous production tasks and it is well documented that words which are lexically less demanding to process (that is more frequent, imageable, concrete or familiar) are named, read, and repeated more efficiently and accurately (Gerhand \& Barry, 1998; Hulme et al., 1997; Laszlo \& Federmeier, 2007; Monsell, Doyle, \& Haggard, 1989; Strain, Patterson, \& Seidenberg, 1995; 2002). This effect is generally interpreted as an index of lexical availability; words which are produced more accurately and efficiently are lexically more available and thus require less processing input for production to be achieved. On the other hand, words which are less frequent and have lower imageability are less available at the word level and require greater amounts of processing input or activation for successful production. Although many studies exploring lexicality effects have focused on picture naming, several existing models provide frameworks that explain these lexicality effects when also observed in repetition and reading. Within connectionist frameworks, computational modelling accounts often divide lexical processing into three distinct processes of semantic, lexical and phonological levels, where activation is transferred interactively across these different levels (Dell et al., 1997; Foygel \& Dell, 2000). Words which are used more frequently are postulated as residing with greater degrees of activation, such that activation spreads more easily and efficiently between levels for words which are highly familiar and frequent, making phonological selection more accurate and production more efficient (Kittredge, Dell, Verkuilen, \& Schwartz, 2008). For tasks of repetition and reading, there is an additional nonlexical processing route to account for the surface word processing that can map phonological/graphemic word information to output 
sounds for production (Dell et al., 2007; Nozari \& Dell, 2013). Both single and dual route frameworks demonstrate effects of lexical variables including frequency, familiarity and age of acquisition, demonstrating a clear contribution of lexical information in reading and repetition processing (Nozari, Kittredge, Dell, \& Schwartz, 2010). Frameworks that are based on a single interactive model for word production make predictions that align with those presented in dual route computational accounts, since phonology and semantics interact and inform one another and, thus, semantic information and activation exerts influence over phonological selection and constrains production to facilitate production of real word patterns (Patterson, Graham, \& Hodges, 1994; Plaut \& Kello, 1999). Behavioural studies examining effects of lexical variables in repetition and reading have demonstrated robust effects of variables such as frequency and imageability (Coltheart, Curtis, Atkins \& Haller 1993; Coltheart, Rastle, Perry, Langdon \& Zeigler 2001, Dell, Martin, \& Schwartz, 2007; Hanley \& Kay, 1997; McCarthy \& Warrington, 1984; Nozari et al., 2010) and this lexicality effect has been replicated in studies of aphasic word repetition and reading (Crisp \& Lambon Ralph, 2006; Hanley, Kay, \& Edwards, 2002; Hirsh, 1998; Jefferies, Crisp, \& Lambon Ralph, 2006). However, people who have Jargon-like aphasia presentations are underrepresented in large scale group studies of aphasia and so it remains unclear whether lexical-semantic information is useful for informing phonological production in participants whose deficits are thought to be predominantly phonological.

There are a small number of studies which focus more specifically on people who have aphasia characterised by phonological impairment. Romani, Galluzzi and Olson (2011) analysed error patterns from six aphasia participants with phonological production deficits on tasks of reading and repetition. They explored whether errors produced by these individuals supported the existence of and contribution from a phonological buffer, indicated by length effects (more probability of phoneme error in longer words) and phoneme position information (phonemes later on in a word were more likely to be errors). Their results demonstrated a lack of buffer-like effects, suggesting that activation of phonemes is supplied and maintained not from a phonological buffer but instead, via the word-lexical representation. These results suggest that phonological production in word repetition and reading is informed by lexico-word level activation. Other examples which include participants with more severe, Jargon-like profiles, 
provide support for the influence of lexical factors such as frequency and imageability over phonological production, demonstrating that production is more accurate when lexical information is more readily available; indicating that lexical information can positively inform phonological processing and increase accuracy in people with more severe phonological deficits (Gotts, della Rocchetta, \& Cipolotti, 2002; Hirsh, 1998). A case series study by Jefferies et al. (2006) describes this effect as reflecting a maximisation of lexical-semantic processing, suggesting that people with specific and significant phonological impairments are inclined to capitalise on other, less impaired, processing components (in this case lexical-semantic information), in an attempt to overcome the phonological impairment. Therefore, enhanced lexicality, frequency and imageability effects are expected from people who present with phonological aphasia (Jefferies et al., 2006; Martin \& Saffran, 1997). However, case studies of individuals with phonological aphasia do not consistently evidence effects of lexical availability in tasks of naming, reading and repetition (Ackerman \& Ellis, 2010; Corbett, Jefferies \& Lambon Ralph, 2008). Nozari and Dell (2013) report on a larger group of aphasia and demonstrate that preserved access to lexical representations and word meaning motivate the use of lexical based processing to accomplish repetition production, whereas impairments in lexical-semantic comprehension limit the ability to recognise and understand a word and therefore push processing more towards nonlexical avenues. It is unclear how successfully people with Jargon and phonological impairment can recruit and use lexical processing to support production, especially since access to lexical and semantic representations tends to be impaired (Robson et al., 2017).

\subsubsection{Nonlexical influences in reading and repetition}

In reading and repetition, it is both possible and probable that surface word information, that is the phonemes and graphemes within a stimulus word, will inform and influence word production processing. The use of these surface features to benefit production is usually referred to as sub-lexical or nonlexical processing. Measuring the influence of these factors is problematic because nonlexical factors such as phonemic and graphemic length co-vary with lexical factors such as frequency and familiarity (Nickels \& Howard, 2004). The phonemic and graphemic length of a stimulus word has been shown to impact on processing and production efficacy in that words which are shorter or contain more frequently used letters have shorter visual fixation periods and 
are produced or responded to more quickly (Baron \& Strawson, 1976; Grainger \& Segui, 1990; Rayner \& Duffy, 1986; Weekes, 1997). In reports of people who have Jargon aphasia, target words with longer phonemic lengths are associated with lower accuracy responses than target words which contain fewer phonemes (Halpern, 1965; Olson et al., 2007). In a study with ten participants who had Jargon aphasia, Pilkington, Sage, Saddy and Robson (2019) demonstrate that greater numbers of nonword errors are produced in tasks of repetition and reading in comparison to picture naming, suggesting that tasks which place greater emphasis on phonological material and nonlexical processing increase Jargon severity. These results indicate that Jargon production is influenced by phonological processing demands and suggest a strong role of phonological processing in the error generation of Jargon nonwords. Therefore, in exploring the influence of lexical variables over production, nonlexical variables must be accounted for and carefully controlled.

\subsubsection{The current study}

The current study aims to gather further information about the influence that the lexical system exerts over phonological production, by exploring how differing amounts of lexical activation impact on phonological production in Jargon aphasia. To accomplish this, words which possess inherently different amounts of lexical activation, for example high and low frequency items, were used in tasks of repetition and reading. The phonological content of target words was matched across testing sets to control for phonological processing demands. The primary research hypothesis was that Jargon production would be increasingly impaired when people processed words that were lexically more demanding/less available in comparison to reading/repeating words that were lexically less demanding/more available. Ten participants with Jargon aphasia completed the repetition and reading tasks. Their responses were quantified by number of nonword errors produced, phonological accuracy within nonwords and phoneme perseveration within nonwords. Jargon aphasia is associated with impairments in auditory comprehension and auditory-phonological analysis (Robson, Grube, Lambon Ralph, Griffiths, \& Sage, 2013), such that lexical comprehension and recognition tends to be poorer in auditory tasks in comparison to written tasks. Therefore, the secondary research hypothesis was that greater effects of lexical availability were expected in word reading, since better lexical-semantic comprehension and access is known to 
maximise lexical mechanisms and minimise nonlexical processing (Nozari \& Dell, 2013). In Jargon aphasia repetition, poorer auditory comprehension should push processing more towards nonlexical avenues, which would elicit fewer lexical effects in word repetition.

\subsection{Materials and methods}

\subsubsection{Participants}

Ethical approval for this study was gained from the School of Psychology and Clinical Language Sciences Research Ethics Committee at the University of Reading (project approval code: 2016-064-HR). The current study details ten individuals (three female; age $\bar{x}=73$ years, $\sigma=11.3$; time post stroke (months, $\bar{x}=35, \sigma=20.75$, see Table 0.1 ) who were identified as having Jargon aphasia according to their language profile on The Boston Diagnostic Aphasia Examination short form (BDAE, Goodglass, Kaplan and Barresi, 2001) and their single word production error profile. The BDAE identified Jargon-like behavioural profiles characterised by impaired auditory comprehension, poor repetition and fluent spoken production (see Figure 0.1). Participants E and J display reduced fluency in relation to that typically reported in people with Jargon aphasia (see Figure 0.1). Both participants produced connected speech with output comprising phrases of four or five items (including words and nonwords) and their remaining language profiles (impaired auditory comprehension and repetition) align with the typical Jargon profile. Furthermore, on single word production tasks their dominant error type is nonwords (see Figure 0.2 ) and therefore they conform to the Jargon aphasia profile. Participant A is the most accurate and scores highly on the repetition subtests, out-performing the rest of the group and deviating from the typical Jargon aphasia profile (see Figure 0.1). His fluency and auditory comprehension align with the typical Jargon profile and his dominant error type is nonwords (see Figure 0.2) hence he was identified as mild Jargon aphasia and included in the current study. On the single word production tasks, all ten participants produced nonword errors more than any other error form, indicating Jargon aphasia (see Figure 0.2). Participants are ranked by the quantity of nonwords produced on experimental testing and are presented in this order throughout, with participant A producing fewest errors and participant J producing the greatest number of nonwords. All participants gave informed consent to participate in the current study. 


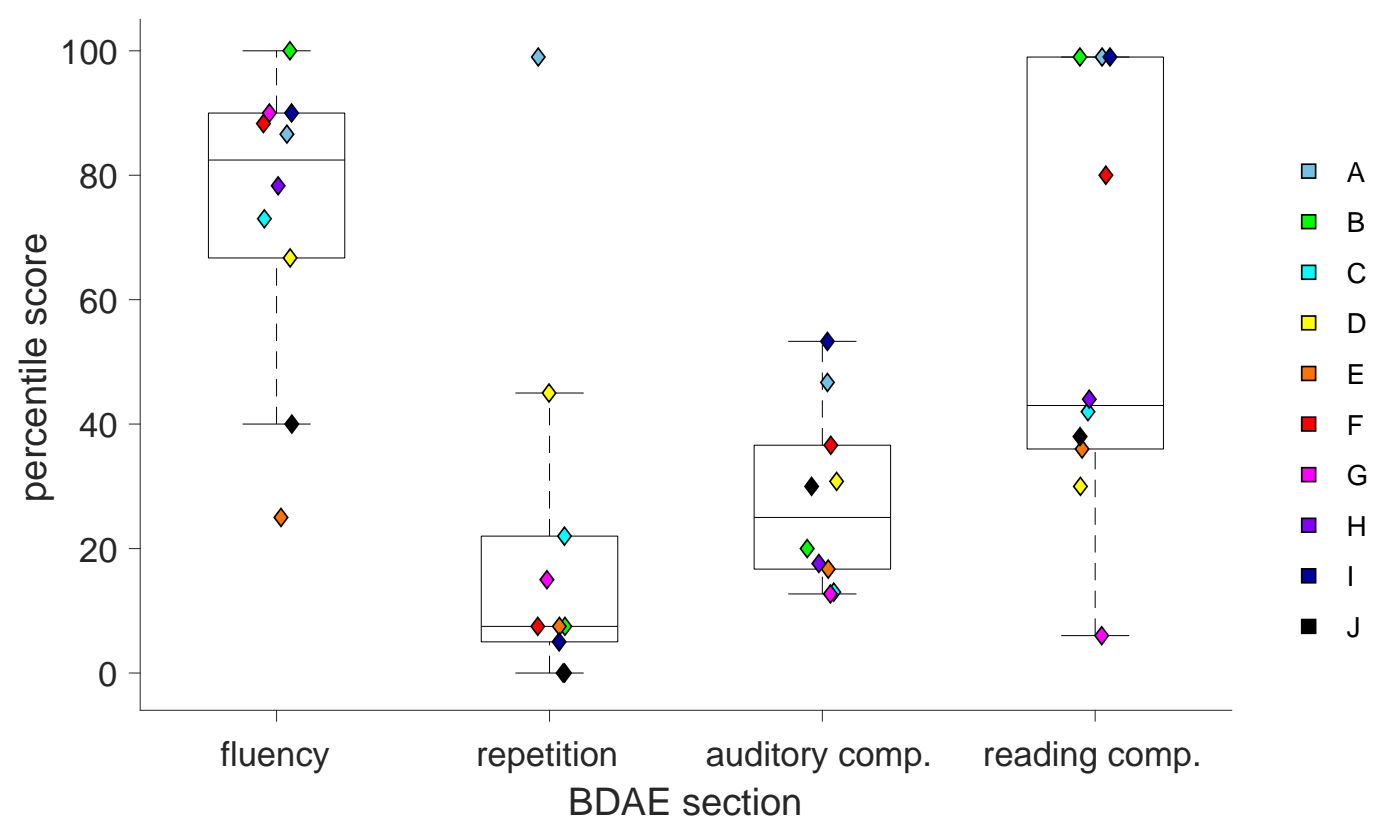

Figure 0.1: Boston Diagnostic Aphasia Evaluation (BDAE) Speech Profiles for Jargon participants, Participant code and colour presented in key; comp. = comprehension.

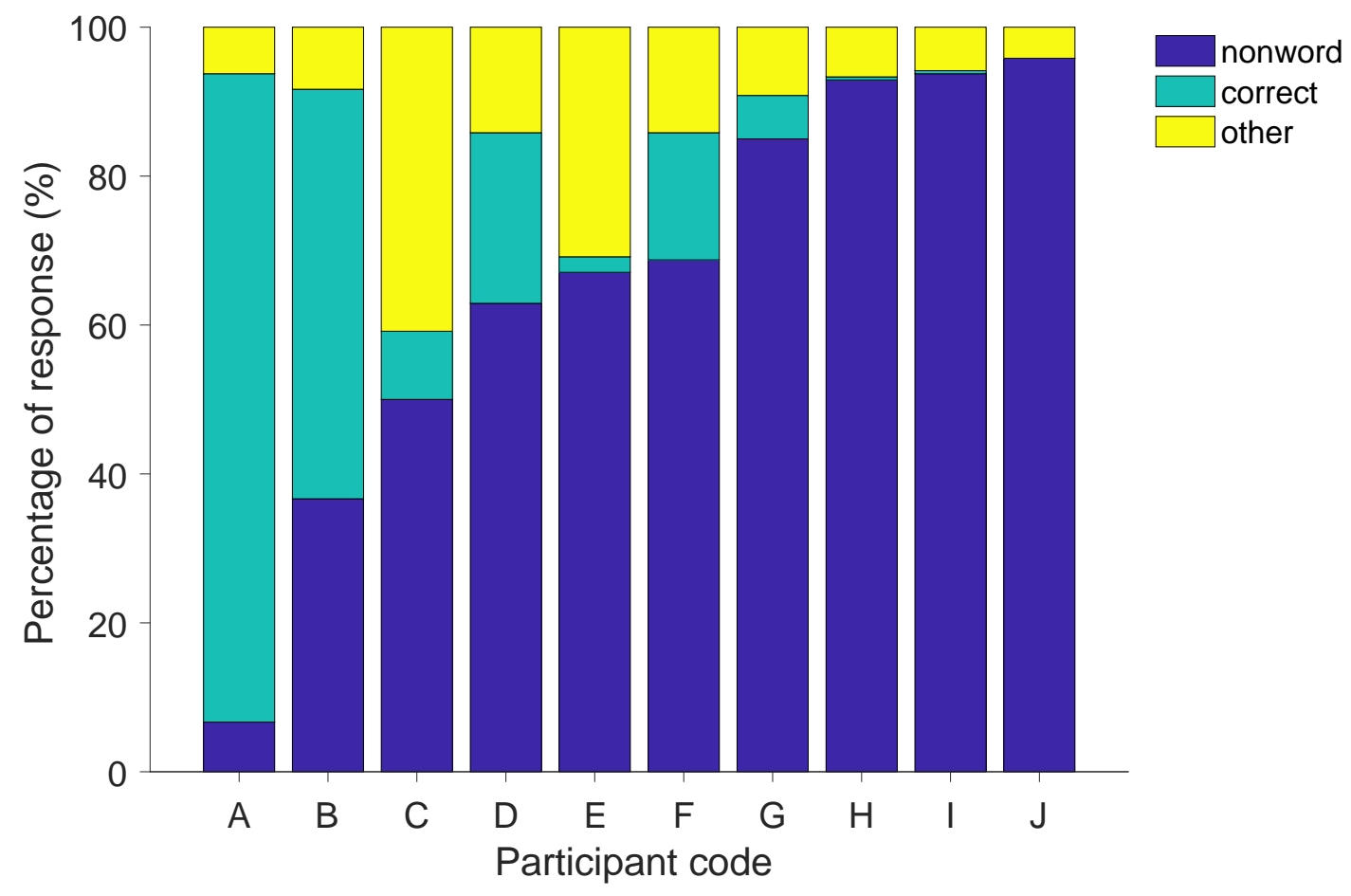

Figure 0.2: Proportion of correct, nonword and other error responses produced on single word production tasks 
Table 0.1: Participant demographic and neurological information.

\begin{tabular}{|c|c|c|c|c|c|c|}
\hline $\begin{array}{c}\text { Participant } \\
\text { Code }\end{array}$ & $\begin{array}{c}\text { Age } \\
\text { (years) }\end{array}$ & Gender & $\begin{array}{c}\text { Time } \\
\text { post } \\
\text { stroke } \\
\text { (months) }\end{array}$ & Aetiology & Lesion & Imaging \\
\hline $\mathrm{A}$ & 90 & M & 27 & Haemorrhagic & pMTG, mMTG, pITG, TPJ & MR \\
\hline \multirow[t]{2}{*}{$\mathrm{B}$} & 71 & M & 78 & unknown & pSTG, mMTG, pMTG, TPJ, IPL & MR \\
\hline & & & & Poor-grade aneurysmal subarachno & & \\
\hline $\mathrm{C}$ & 56 & $\mathrm{~F}$ & 37 & haemorrhage & ATL, pSTG, aSTG, TPJ & $\mathrm{CT}$ \\
\hline \multirow[t]{2}{*}{$\mathrm{D}$} & 62 & M & 11 & Complete left carotid occlusion & - & Unavailable \\
\hline & & & & & aSTG, pSTG, mMTG, pMTG, pITG, & \\
\hline $\mathrm{E}$ & 71 & M & 57 & Ischemic, secondary to surgery & TPJ, IPL & MR \\
\hline $\mathrm{F}$ & 74 & $\mathrm{~F}$ & 9 & Ischemic & ATL, mMTG, mITG, TPJ, IPL, MFG & $\mathrm{CT}$ \\
\hline G & 78 & M & 24 & Haemorrhagic & pSTG, mMTG, mITG, TPJ, IPL, occ & MR \\
\hline $\mathrm{H}$ & 61 & M & 42 & Ischemic and haemorrhagic & aSTG, pSTG, TPJ & MR \\
\hline $\mathrm{I}$ & 85 & M & 33 & Ischemic & pSTG, pMTG, TPJ, IPL & MR - clinical \\
\hline $\mathrm{J}$ & 84 & $\mathrm{~F}$ & 58 & unknown & - & Unavailable \\
\hline
\end{tabular}

$\mathrm{p}$ = posterior; $\mathrm{m}$ = mid; $\mathrm{a}$ = anterior; STG = superior temporal gyrus; MTG = middle temporal gyrus; ITG = inferior temporal gyrus; TPJ = temporoparietal junction; IPL = inferior parietal lobule; MFG = middle frontal gyrus. 


\subsubsection{Neuroimaging}

Lesion profiles are presented for the eight participants for whom neuroimaging data were available (see Figure 0.3). Imaging data were unavailable for participants D and J and they were unable to attend for scanning. T1-weighted MR research images were available for five individuals (A, B, E, G, and H), acquired on a Siemens Magnetom Trio 3T MRI scanner. Clinical CT scans were available for two participants ( $\mathrm{C}$ and F) and a clinical MR was available for participant I. Lesion masks were drawn manually using MRIcron software (Rorden \& Brett, 2000) and normalised using SPM8 (https://www.fil.ion.ucl.ac.uk/spm). The normalised masks were overlaid using MRIcron. Complete overlap ( $n=8)$ was observed in a small number of voxels located at the junction of left superior temporal and inferior parietal lobe. High overlap $(n=7)$ was evident in a larger area including the left posterior middle temporal gyrus and superior temporal gyrus, conforming with lesion profiles typically reported in Jargon aphasia (Kertesz, 1981; Hillis, et al., 1999). Information about individual stroke onset, aetiology and lesion profile is provided in Table 0.1 .

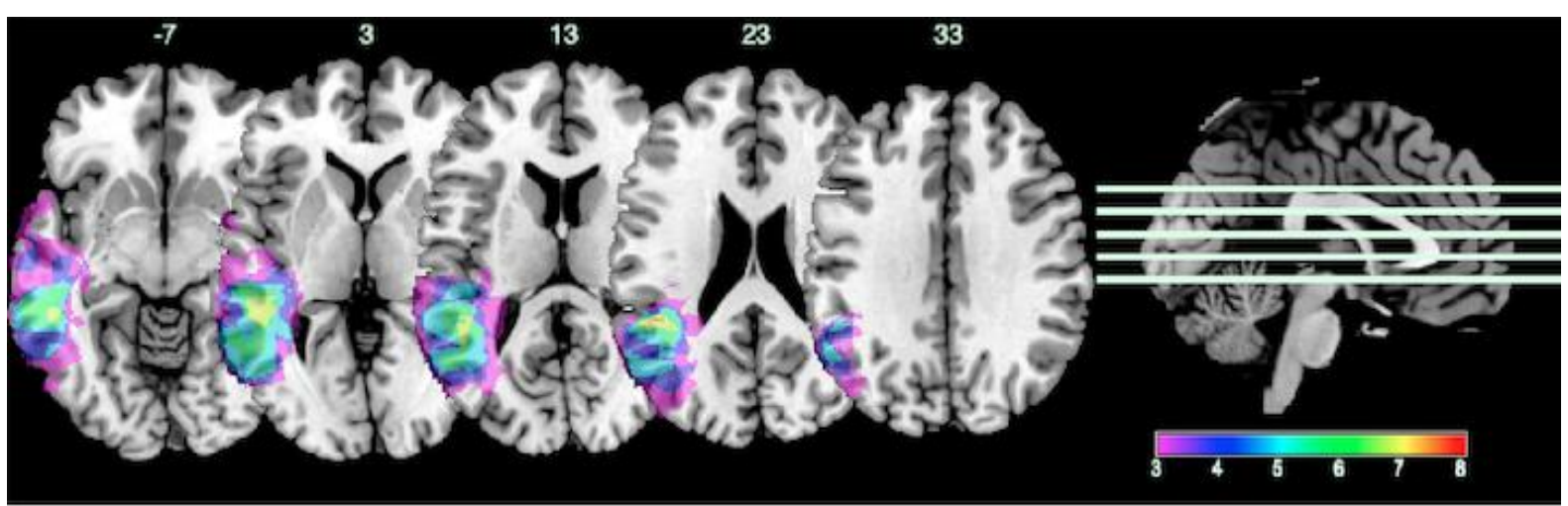

Figure 0.3: Lesion overlay identifying common regions of damage. MNI Z co-ordinate presented above each image. Colour bar indicates number of participants with lesion at each voxel $(3 \geq n \geq 8)$.

\subsubsection{Background testing}

All participants were tested on semantic knowledge using both pictorial (Camel and Cactus, (CCT; Adlam, Patterson, Bozeat, \& Hodges, 2010) and written (96 synonym judgement; Jefferies, Patterson, Jones, \& Lambon Ralph, 2009) stimuli. Initial phoneme segmentation and written rhyme judgement tasks were administered (Psycholinguistic Assessment of Language Processing in Aphasia, PALPA; Kay, Lesser, \& Coltheart, 1996) 
to assess phonological processing ability. To test basic visual processing, the shape detection screen and the position discrimination test from the Visual Object and Space Perception battery (VOSP, Warrington \& James, 1991) were used. The shape discrimination screen is designed to identify presence of visual processing impairment such that no further testing should be done, and the participant be referred for specialist review; all participants in the current study passed this screen (see Table 0.2). The position discrimination test provides information on the patient's ability to perceive relative positions of objects in space. An in-house letter matching test was developed and used to assess whether participants were able to visually identify matching letter shapes. Participants were asked to match a probe grapheme, bigram or trigram to a target presented within an array of three distracters, presented in different fonts. As a marker of executive functioning, the trail making task from the Oxford Cognitive Screen (Demeyere, Riddoch, Slavkova, Bickerton, \& Humphreys, 2015) was administered. The first two trail tasks required participants to link triangles and circles, respectively, in descending size order. For the third trial, participants were required to switch between circles and triangles, adhering to the descending size rule applied to the first two trail tests. Scores are reported separately for the non-switching and switching tasks according to successful connections made and a final executive score is calculated and used to identify presence of executive impairment.

Severe impairment in phonological processing skills (measured by phoneme segmentation) was observed at the group level and for all participants across the caseseries. Additional, although less severe, impairment in semantic processing was observed at the group level and the case-series pattern revealed greater variation in the degree of semantic impairment across participants, with A, B, F, and I demonstrating more persevered semantic processing in comparison to participants $C, D, G$ and $H$. The majority of the group presented with intact visual perception and processing ability indicated by high scores on the VOSP and letter matching tests apart from participants C and $G$ who were identified as having impairments in visual perception by the position discrimination subtest (VOSP 2; see Table 0.2). Both participants C and G were also identified as having impaired executive functioning by the trail making tasks. They scored full marks on the single trail task (joining circles/triangles in descending size order) suggesting their visual deficit did not impact their ability to detect shape sizes 
and positions and that their impaired executive score validly indexes impaired executive control (see Table 0.2 ). Both participants $C$ and G demonstrated impairment in grapheme matching suggesting impaired ability to detect letter shapes. This was mild for participant C ( $82 \%$ accuracy) and severe for participant G (45\%). Participant J also presents with executive functioning impairment (see Table 0.2). 
Table 0.2: Participant raw and percentage () scores on semantic, phonological, visual processing assessments and executive assessments.

\begin{tabular}{|c|c|c|c|c|c|c|c|c|c|c|}
\hline $\begin{array}{c}\text { Participant } \\
\text { Code }\end{array}$ & $\begin{array}{c}\text { Camel \& } \\
\text { Cactus } \\
n=64\end{array}$ & $\begin{array}{c}96 \\
\text { synonym } \\
n=96\end{array}$ & $\begin{array}{c}\text { Initial } \\
\text { phoneme } \\
\text { segmentation } \\
n=45\end{array}$ & $\begin{array}{c}\text { Rhyme } \\
\text { detection } \\
n=60\end{array}$ & $\begin{array}{c}\text { Letter } \\
\text { matching } \\
n=22\end{array}$ & $\begin{array}{c}\operatorname{VOSP}(1) \\
n=20\end{array}$ & $\begin{array}{c}\operatorname{VOSP}(2) \\
n=20\end{array}$ & $\begin{array}{c}\text { Trail } \\
\text { making } 1 \\
n=12\end{array}$ & $\begin{array}{c}\text { Trail } \\
\text { making } 2 \\
n=13\end{array}$ & $\begin{array}{c}\text { Executive } \\
\text { Score }\end{array}$ \\
\hline A & $42(66)^{*}$ & $80(83)^{*}$ & $35(78)^{*}$ & $53(88)$ & $20(91)$ & $19(95)$ & $20(100)$ & $12(100)$ & $12(92)$ & 0 \\
\hline B & $59(92)^{*}$ & $91(95)^{*}$ & $22(49) *$ & $47(78)$ & $22(100)$ & $20(100)$ & $20(100)$ & $12(100)$ & $13(100)$ & -1 \\
\hline $\mathrm{C}$ & $28(44)^{*}$ & $41(43)^{*}$ & $11(24)^{*}$ & $32(53)$ & $18(82)$ & $18(90)$ & $17(85)^{*}$ & $12(100)$ & $8(62)$ & $4^{*}$ \\
\hline D & $36(56)^{*}$ & $39(41)^{*}$ & $15(33)^{*}$ & $32(53)$ & $22(100)$ & $20(100)$ & $20(100)$ & $12(100)$ & $10(77)$ & 2 \\
\hline E & $49(77)^{*}$ & $50(52)^{*}$ & $10(22)^{*}$ & $34(57)$ & $22(100)$ & $20(100)$ & $20(100)$ & $12(100)$ & $13(100)$ & -1 \\
\hline $\mathrm{F}$ & $51(80)^{*}$ & $84(88)^{*}$ & $23(51)^{*}$ & $32(53)$ & $22(100)$ & $20(100)$ & $19(95)$ & $12(100)$ & $13(100)$ & -1 \\
\hline G & $36(56)^{*}$ & $33(34)^{*}$ & $9(20)^{*}$ & $29(48)$ & $10(45)$ & $19(95)$ & $16(80)^{*}$ & $12(100)$ & $7(54)$ & $5^{*}$ \\
\hline $\mathrm{H}$ & $39(61)^{*}$ & $35(36)^{*}$ & $19(42)^{*}$ & $28(47)$ & $21(95)$ & $19(95)$ & $19(95)$ & $11(92)$ & $13(100)$ & -2 \\
\hline I & $48(75)^{*}$ & $91(95)^{*}$ & $9(20)^{*}$ & $46(77)$ & $20(91)$ & $18(90)$ & $20(100)$ & $12(100)$ & $13(100)$ & -1 \\
\hline $\mathrm{J}$ & $41(64)^{*}$ & $62(65)^{*}$ & $12(27)^{*}$ & $30(50)$ & $21(95)$ & $20(100)$ & $20(100)$ & $10(83)^{*}$ & $6(46)$ & $4^{*}$ \\
\hline Mean & $42.9(67)$ & $60.6(63)$ & $16.5(36)$ & $36.3(60)$ & $19.8(90)$ & $19.3(96.5)$ & $19.75(96)$ & $11.7(97.5)$ & $10.8(83)$ & \\
\hline Cut off & $53(83)$ & $92(96)$ & $39(86)$ & - & - & $15(75)$ & $18(90)$ & $10(83) \bullet$ & $4(31)$ & 4 \\
\hline
\end{tabular}

Note: Participants presented in order of nonword production prevalence; $n=x$ refers to total item number per assessment; 96 synonym: 96 written synonym judgement; VOSP(1): Visual Object and Space Perception battery screening test; VOSP(2): Visual Object and Space Perception battery position discrimination; $\bullet$ trail making 1 comprises two separate tests with cut offs of 5 and 5.85, a combined threshold of 10 is adopted, * denotes impaired performance. 


\subsubsection{Stimuli generation}

Two hundred and forty words were selected from the MRC psycholinguistic database (Coltheart, 1981) (see Appendix 1 for word sets). These 240 words were organised into four separate sets of 60 items according to psycholinguistic properties related to lexical processing demands, as obtained from the MRC database (see Appendix 2).

Independent one-way ANOVAs were used to statistically confirm that the lexical psycholinguistic properties varied across the four sets and that variables relating to phonological and graphemic processing were held constant. Two of the four sets had significantly lower values for frequency (KF, Celex/logged), concreteness, imageability and familiarity (MRC database statistics). Tukey post hoc tests were used and $p \leq .001$ was applied to post-hoc comparisons. All four word sets were matched for the phonological components; phonemic length, syllable length and number of letters $(p \geq$ .893). The English Lexicon Project (ELP; Balota et al., 2007) database was used to extract orthographic and phonological neighbourhood density statistics for the four word sets. There was no difference observed across the four separate sets $(p \geq .230)$. The phonotactic probability calculator (Vitevitch \& Luce, 2004) was used to obtain values for position specific frequency of phonemes and biphones. There were no differences in phonotactic probability calculations across the four word sets $(p \geq .765)$. The ELP data for bigram position specific frequency also indicated no difference across the four word sets ( $p=.320)$. Error! Reference source not found. sets out the mean and standard deviation data for psycholinguistic variation across the four-word sets. From herein, the two word sets with higher frequency, imagability, concreteness and familiarity values will be labelled 'high' to reflect their lexical availability, whilst the remaining two sets will be labelled 'low', in accordance with their lower availability. One high and one low set were used for word repetition and the remaining high and low sets were used for word reading.

\subsubsection{Procedure}

Data were collected by the first author and all participants were visited in their own homes. For word repetition, the target words were pre-recorded, to control for variability in production across time points and participants. The single word recordings were then presented for repetition during data collection. A fixation cross was present at the centre of the screen throughout the repetition testing. For word 
reading single written words were presented in the centre of a laptop computer screen. In between the words, a fixation cross was presented for $1000 \mathrm{~ms}$. Participants were instructed to repeat/read the target word aloud to the best of their ability. No explicit time pressure was applied. The experimenter moved participants onto the next target word following three unsuccessful attempts at production. Participants read/repeated all 60 words from a single set consecutively, without breaks. Task and difficulty conditions were administered in a counterbalanced order across participants. Audio recordings were taken throughout testing and participants' responses were transcribed in broad phonemic transcription in real time and subsequently checked against the recording before electronic data entry. Electronic transcriptions were coded in DISC symbols which have 1:1 phoneme-symbol correspondence (e.g. $/ \mathrm{u}: /=\mathrm{u}$ ) to enable automated data analysis, using Microsoft Excel and MATLAB. Participant B produced semantic errors in word repetition and so these data are omitted from the current analysis. Participant $\mathrm{C}$ was unable to produce any verbal response to written words. The background testing scores indicate that she presents with mild impairment on both the position discrimination task and the letter matching task (see Figure 2) and moderate written word comprehension (see Figure 1). It is beyond the scope of the current study to further test and diagnose the nature of her dyslexia. Due to her inability to produce any verbal response to written stimuli and the subsequent emotional stress placed on her as a result of this task, reading aloud was not completed with this individual.

\subsubsection{Recording and error analysis}

Responses were coded based on criteria presented in Dell et al., (1997) with lexical (real word) responses categorised as correct or not and incorrect lexical responses categorised as 'other' error types. Other error types consisted of formal errors, denoting when a real word response was phonologically related to the target in either initial phoneme or there was 50\% phonological overlap between the target and the response; unrelated errors, when a real word error had no semantic or phonological relationship to the target; semantic when the response was related in meaning to the target word; mixed, indicating that the response has both a semantic and phonological relationship to the target; and a non-response, when the participant produced no verbal response or indicated that they did not know. Non-lexical errors (a string of phonemes that do not constitute a word in the English language) were identified and labelled as nonwords. 
Error numbers were inspected to confirm that nonword errors were most common, indicating the presence of Jargon aphasia (see Figure 2, Appendix 3). Subsequent analyses focused solely on nonwords because of their dominance and relevance in Jargon aphasia. To explore whether nonword Jargon production is influenced by lexical availability, a repeated measures factorial ANOVA was used to identify whether the number of nonwords differed under the lexical availability (high and low) or task (repetition and reading) conditions at the group level. Participants B and C are excluded from this repeated measures analysis due to incomplete data sets. Case-series analyses were then conducted using individual Fisher's tests were used to determine whether there was an effect of lexical availability on the number of nonwords produced by each participant on the separate production tasks.

\subsubsection{Phonological accuracy analysis}

The Phonological Overlap Index measure (POI; Schwartz et al., 2004) was used to quantify how many phonemes a nonword contained in relation to its target word form. The POI formula,

\section{Number of phonemes shared between response and target $\mathrm{x} 2) /$ (total phonemes in target + total phonemes in response)}

assigns nonwords a value between zero and one. By this calculation, nonwords containing no target phonology obtain a value of zero (e.g. "earth", /bændrıə//) and nonwords containing higher proportions of target phonology obtaining scores closer to one (e.g. "mortal", /mэiltə/). Whilst both errors would be categorised as nonwords in the first analysis, the POI metric provides more detail about the degree of phonological disruption within errors, meaning production can be quantified with greater sensitivity. The POI was calculated for all nonword responses produced by each participant to determine whether higher availability words exerted greater constraint and generated more accurate phonological production, in comparison to words with lower lexical availability when phonological constraints were controlled for. A repeated measures factorial ANOVA was used to determine whether there was an effect of lexical availability (high and low) or task (repetition and reading) at the group level and independent non-parametric t tests were used to explore the effect of lexical availability 
(high and low) on nonword POI for each participant across repetition and reading separately.

\subsubsection{Perseveration analysis}

The current measure of perseveration is presented in an unpublished thesis (Godbold, 2017) and is adapted from methods presented in McCloskey, Macaruso, and Rapp (2006). For this analysis, all intruded (erroneous) phonemes within a given nonword response are identified and then searched for within the previous production. The number of intruded phonemes found within the immediate production is summed and divided by the total number of intrusions, quantifying how many phoneme errors are perseverations. For example, participant J repeated the target word 'wedding' as /gpresd/, intruding the four phonemes /g/, /p/, /r/ and /eI/. The preceding response /gpred/ contained three of these error phonemes (/g/, /p/ and /r/), generating an intrusion-perseveration score of 0.75. By this calculation, each nonword response is assigned an intrusion-perseveration score, which falls between zero (indicating errors were not present in the immediately preceding response) and one (indicating all errors were produced on the immediately preceding production). Where multiple occurrences of phonemes are produced within a single response, only 1:1 intrusion - previous production matches are counted. This method identifies phoneme perseverations produced within the previous production only. Phoneme perseverations are most commonly observed across responses in close proximity to a source production, at a lag of one, two or three responses, with errors produced later in time (at a lag of 4 onwards) bearing only chance perseverative relationships (Cohen and Deheane, 1998). The current measure focused on a response lag of one as phoneme perseverations are most significant and consistent at this temporal resolution (Ackerman \& Ellis, 2007; Corbett et al., 2008; Martin \& Dell, 2007) and therefore would sufficiently index Jargon production for the current hypothesis testing.

A repeated measures factorial ANOVA was used to determine whether there was an effect of lexical availability (high and low) or task (repetition and reading) on the intrusion-perseveration score at the group level for the 7 participants of the eight participants with complete data sets. Participant A was not included in the perseveration analyses as he produced insufficient errors in the reading tasks to allow a 
perseveration analysis to be carried out (he made one error in the highly available reading task and three errors in the low availability condition; see Appendix 3). Independent non-parametric $t$ tests were used to explore the effect of lexical availability (high and low) on perseveration for each participant, across reading and repetition separately.

\subsubsection{Summarising the lexicality effect}

For each individual, the statistics identified by the three separate production measures (nonword number, phonological accuracy and intrusion-perseveration score) were used to deduce a difference score. This was done in the direction of the hypothesis, e.g. nonword number for the low availability word set minus nonword number for the high availability word set. The group mean and standard deviation of the difference scores was calculated for each of the three production measures, for repetition and reading separately. The mean was then deducted from each individual difference statistic and divided by the standard deviation to deduce a $\mathrm{Z}$ score for each difference statistic. By this approach, a greater $\mathrm{Z}$ score represents a higher difference statistic in the direction of the hypothesis, e.g. nonword number in the low availability word set was greater than nonword number observed in the high availability word set, in relation to the difference statistics across the rest of the group. This approach was adopted to support identification of individuals who exhibited most behavioural difference in response to the lexical availability manipulation. The difference statistics were entered into separate repeated measured non-parametric $t$ tests to determine whether the difference scores were different between repetition and reading. Data from the eight participants with complete datasets were entered into this analysis.

\subsection{Results}

\subsubsection{Nonword prevalence}

All ten participants produced nonwords as the dominant error type (see Figure 0.2). Participant A produced the fewest nonword errors with approximately seven percent of his responses labelled as nonwords and participant J presented with the most severe Jargon output, with responses comprising 96\% nonwords (see Figure 0.2, Appendix 3). Four participants (C, D, E and F) produced notable numbers of 'other' errors (see Appendix 3). For participant C, other errors were either real word errors that were 
unrelated to the target (13\%), real word errors that were phonologically related to the target (8\%), or non-responses (19\%). Participant D produced real word errors that were either phonologically related (9\%) or unrelated to the target (5\%). For participant E, the majority of other errors were either real words with no phonological or semantic relationship to the target word (16\%) or real word errors that were phonologically related to the target (15\%). Data inspection indicated that unrelated real-word error productions appeared to arise from whole word perseverations and/or idiosyncratic productions. Participant F's other error productions were either phonologically related $(8 \%)$ or unrelated $(4 \%)$ real word responses. The remaining six participants $(A, B, G, H$, I and J) produced other error responses less than $10 \%$ of the time (see Figure 0.2). On inspection, all nonword errors conformed to English phonotactics.

A repeated measures factorial ANOVA was used to determine whether lexical availability (high or low) or production task (reading and repetition) influenced the number of nonwords produced. Results indicated that there was a main effect of lexical availability $\left(\mathrm{F}(1,7)=7.627, p=.028, \eta \mathrm{p}^{2}=.521\right)$ demonstrating that more nonwords were produced when targets were less available (high $\overline{\mathrm{x}}=39.4$, low $\overline{\mathrm{x}}=46.5$ ). There was no main effect of production task $\left(\mathrm{F}(1,7)=1.292, p=.293, \eta p^{2}=.156\right.$, see Figure 0.4 ) and no interaction between task and lexical availability $(F(1,7)=2.517, p=.157$, $\left.\eta p^{2}=.264\right)$. As participant $B$ and $C$ have incomplete data sets, they are discounted from the group level repeated measures analysis. 


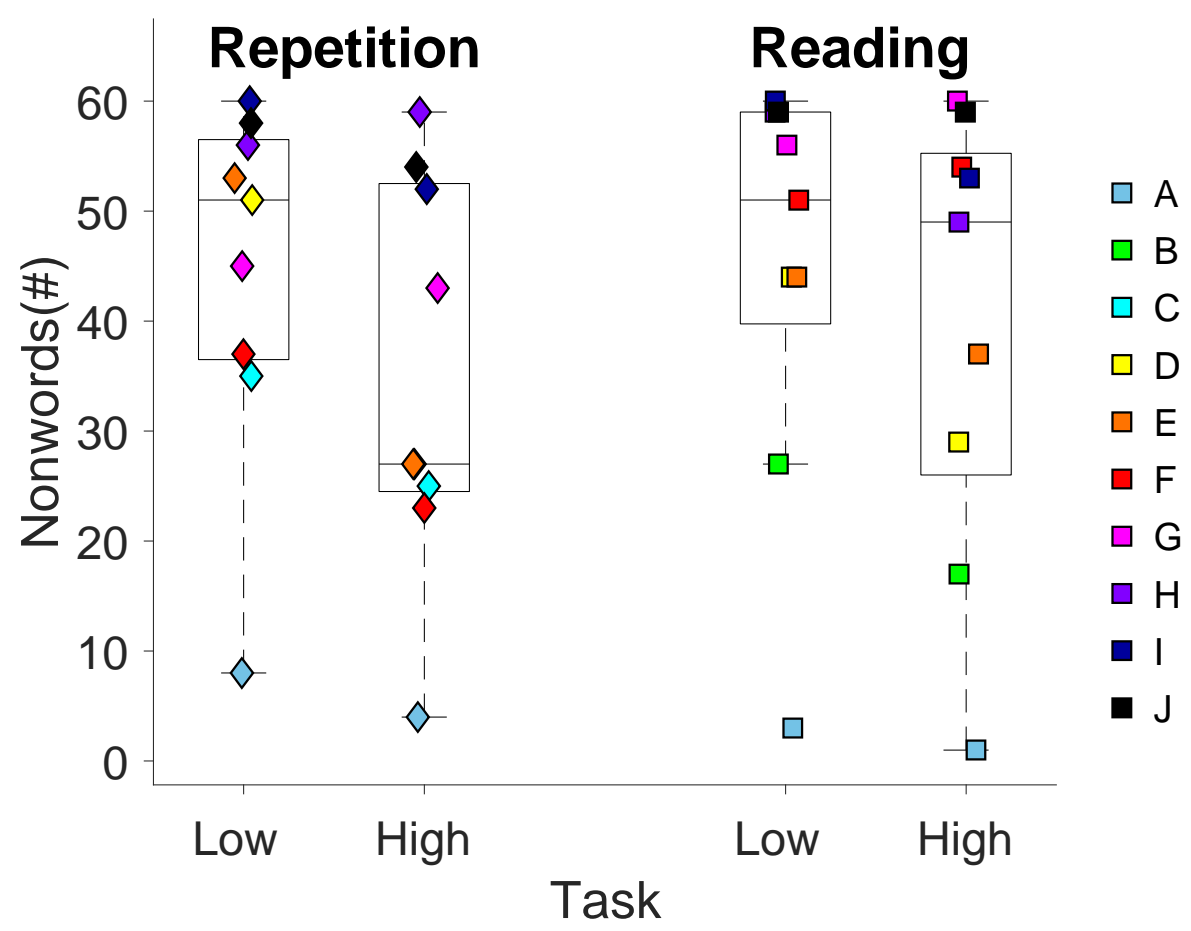

Figure 0.4: Number of nonwords produced on low and high availability word sets for repetition and reading. Individual markers indicate total nonwords produced by each participant. Participant colours presented in key.

At the individual level, eight of the nine participants produced more nonwords in the low availability repetition task. Fisher's exact test identified that this was statistically significant in participants D, E, F and I ( $p \leq .006$, see Table 3). Participant H produced marginally more nonwords in the highly available condition; however, this was not statistically significant ( $p=0.364$ ). In word reading, seven participants produced more nonwords when the target lexical item was less available. This was statistically significant in participants D, H and I ( $p \leq .013$, see Table 3). Participants F and G produced more nonwords on the highly available word reading set; however, these effects did not reach statistical significance $(p \geq 119)$. 
Table 0.3: Number of nonwords and Fishers $p$ test statistics for lexicality effect on number of nonwords in repetition and reading.

\begin{tabular}{ccccccc}
\hline & \multicolumn{3}{c}{ Repetition } & \multicolumn{3}{c}{ Reading } \\
\hline Participant & Low & High & Fishers $p$ & Low & High & Fishers $p$ \\
\hline A & 8 & 4 & .362 & 3 & 1 & .619 \\
B & - & - & - & 27 & 17 & .088 \\
C & 35 & 25 & .100 & - & - & - \\
D & 51 & 27 & $\leq .001$ & 44 & 29 & .009 \\
E & 53 & 27 & $\leq .001$ & 44 & 37 & .242 \\
F & 37 & 23 & .006 & 51 & 54 & .582 \\
G & 45 & 43 & .837 & 56 & 60 & .119 \\
H & 56 & 59 & .364 & 59 & 49 & .004 \\
I & 60 & 52 & .006 & 60 & 53 & .013 \\
J & 58 & 54 & .272 & 59 & 59 & 1.000 \\
\hline
\end{tabular}

\subsubsection{Phonological accuracy}

A repeated measures ANOVA was used to determine whether there was an effect of lexical availability (high or low) or task (repetition and reading) on phonological production accuracy (POI) of nonwords at the group level. The POI measure quantifies nonword accuracy on a scale ranging from 0 to 1 , where 0 indicates no phonological overlap and 1 indicates all target phonemes were produced. The ANOVA demonstrated that there was no significant effect of lexical availability $\left(\mathrm{F}(1,7)=1.308, p=.290, \eta \mathrm{p}^{2}=\right.$ $.157)$, production task $\left(\mathrm{F}(1,7)=2.190, p=.182, \eta p^{2}=.238\right)$, or interaction effect $(F(1,7)$ $=.321, p=.589, \eta p^{2}=.044 ;$ see Figure 0.5). 


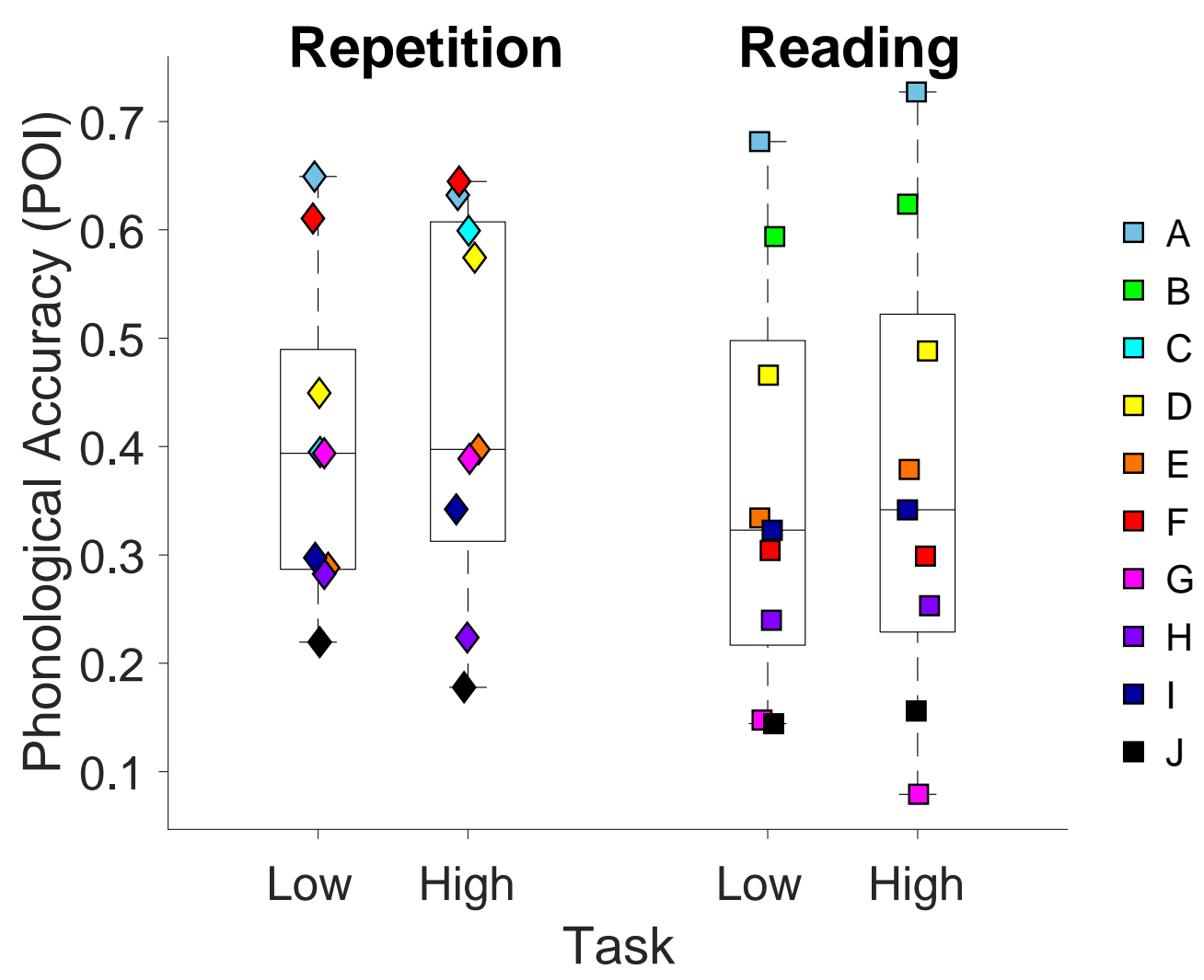

Figure 0.5: Mean Phonological Overlap Index (POI) for low and high availability word sets for repetition and reading. Individual markers indicate participant means. Participant colours presented in key.

At the individual level, nonparametric $t$ tests identified that participants $C$ and $D$ were more phonologically accurate when repeating the easier, highly available word set ( $p \leq$ .017 , see Table 0.4, Figure 0.6). The remaining seven participants demonstrated no effect of lexical availability on the phonological accuracy of nonwords ( $p \geq .059$, see Table 0.4 Figure 0.6). In word reading, participant G produced more target phonology when lexical items were less accessible ( $p=.016$; see Figure 6 ). The remaining eight participants demonstrated no effect of lexical availability on their nonword accuracy in word reading ( $p \geq .256$, see Figure 0.6$)$. 
Table 0.4: Mann Whitney U test statistics for lexicality effect on POI in repetition and reading per participant.

\begin{tabular}{ccccc}
\hline & \multicolumn{2}{c}{ Repetition } & \multicolumn{2}{c}{ Reading } \\
\hline Participant & $U$ & $P$ & $U$ & $p$ \\
\hline A & 15 & .798 & - & - \\
B & - & - & 206 & .570 \\
C & 212 & .001 & - & - \\
D & 462 & .017 & 592 & .599 \\
E & 531 & .059 & 695 & .256 \\
F & 363 & .336 & 1361 & .915 \\
G & 953 & .903 & 1288 & .016 \\
H & 1346 & .085 & 1399 & .770 \\
I & 1369 & .263 & 1375 & .727 \\
J & 1362 & .226 & 1698 & .813 \\
\hline
\end{tabular}



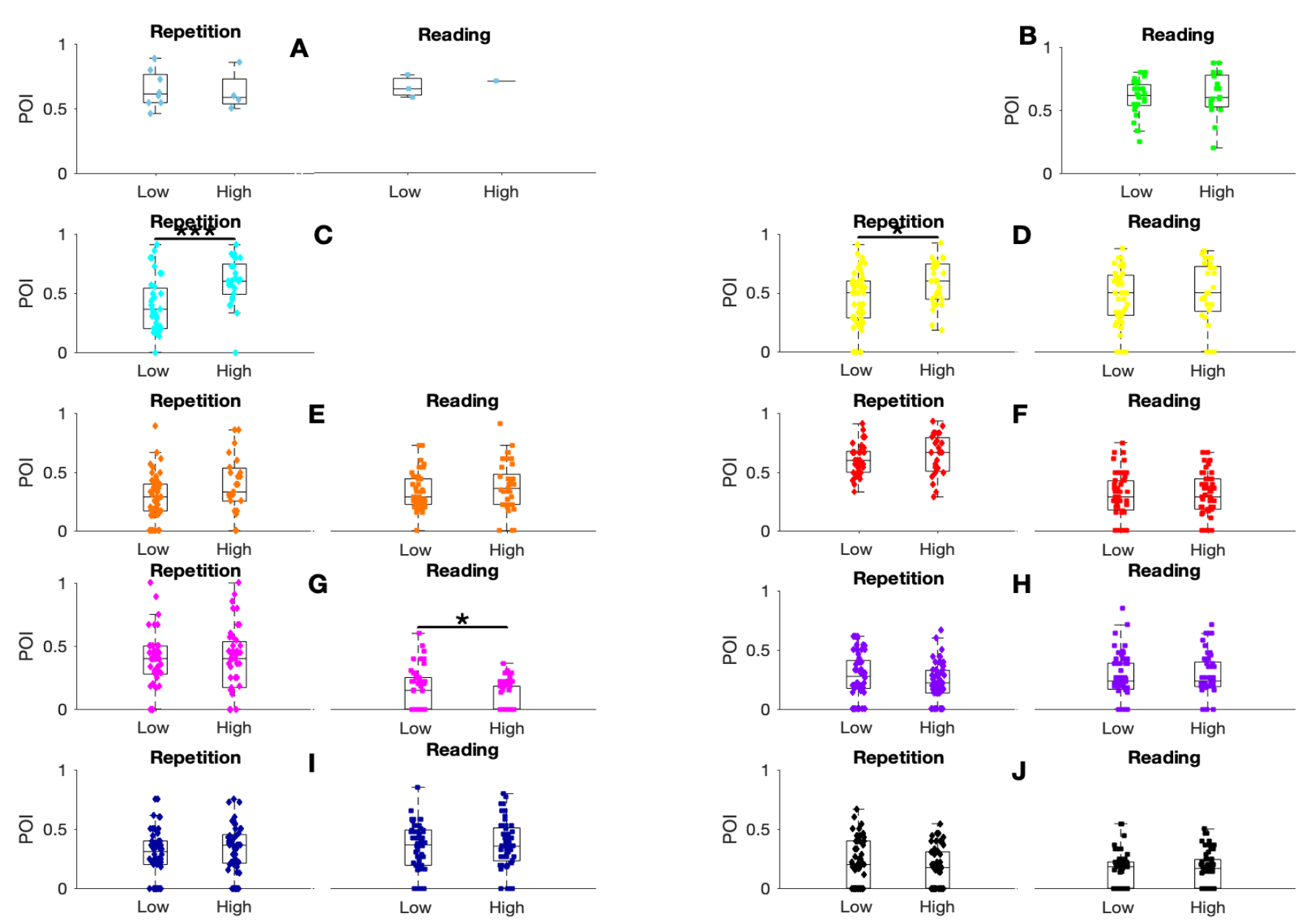

Figure 0.6: Phonological Overlap Index scores and distributions for nonword errors produced by each participant in the high and low availability conditions in repetition and reading. Stars indicate significance levels: $p \leq .05^{*}, p \leq .01^{* *}, p \leq .001^{* * *}$ 


\subsubsection{Perseveration}

The perseveration calculation assigned every nonword response an intrusionperseveration score between zero and one, quantifying the likelihood that phoneme errors within nonwords were present in the immediately preceding production. For the group level analysis average perseveration scores for the seven individuals with complete data sets were entered into a repeated measures factorial ANOVA to examine whether lexical availability and production task influenced perseveration. Participant A is excluded from this analysis since he produces insufficient errors in word reading for this analysis (see Table 3). Results demonstrated no effect of lexical availability $(F(1,6)$ $=2.129, p=.296, \eta p 2=.179)$, production task $(\mathrm{F}(1,6)=2.129, p=.195, \eta p 2=.262)$ or interaction $(F(1,6)=1.853, p=.222, \eta p 2=.236)$, indicating perseveration rates were similar across the different tasks and conditions (see Figure 7).

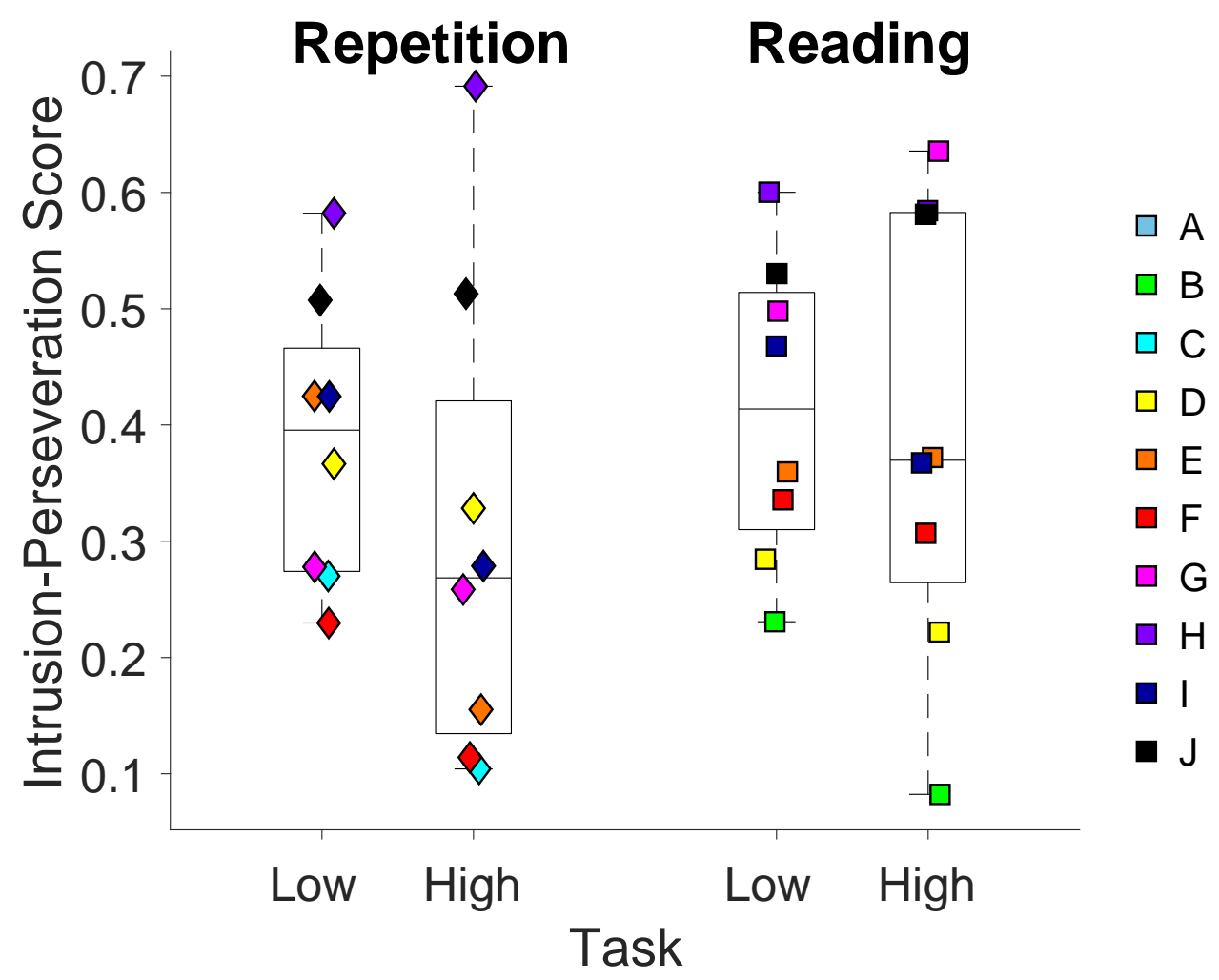

Figure 0.7: Mean intrusion perseveration score for low and high availability word sets for repetition and reading. Individual markers indicate participant means. Participant colours presented in key. 
Individual non-parametric $t$ tests identified that, in repetition, participants $\mathrm{C}, \mathrm{E}$ and I were more perseverative when lexical availability was less $(p \leq .038$, see Table 5 , Figure 7). Participants A, D, F, G and J exhibited no differences in their perseveration across the lexicality conditions in repetition ( $p \geq .267$, see Table 5 , Figure 8 ) and participant $H$ produced more perseveration when lexical availability was higher $(p=.020)$. In word reading, rates of perseveration were similar for all individuals $(p \geq .074)$ apart from participant $\mathrm{G}$ who was more perseverative when lexical availability was higher $(p=$ .008, see Table 0.5, Figure 0.8: Intrusion-perseveration scores and distributions for nonword errors produced by each participant in the high and low availability conditions in repetition and reading. Stars indicate significance levels: $p \leq .05^{*}, \mathrm{p} \leq .01^{* *}, \mathrm{p} \leq$ $\left..001^{* * *}.\right)$.

Table 0.5: Mann Whitney U test statistics for lexicality effect on intrusion-perseveration score in repetition and reading for each participant.

\begin{tabular}{ccccc}
\hline & \multicolumn{2}{c}{ Repetition } & \multicolumn{2}{c}{ Reading } \\
\hline A & U & $p$ & $\mathrm{U}$ & $p$ \\
B & 12.0 & .418 & - & - \\
C & - & - & 155.0 & .122 \\
D & 294.0 & .038 & - & - \\
E & 634.5 & .400 & 553.0 & .373 \\
F & 372.5 & .001 & 743.0 & .756 \\
G & 357.5 & .267 & 1323.5 & .992 \\
H & 875.5 & .664 & 1158.0 & .008 \\
I & 1242.0 & .020 & 1370.5 & .891 \\
J & 983.0 & .002 & 1101.0 & .074 \\
& 1542.5 & .902 & 1538.5 & .426 \\
\hline
\end{tabular}



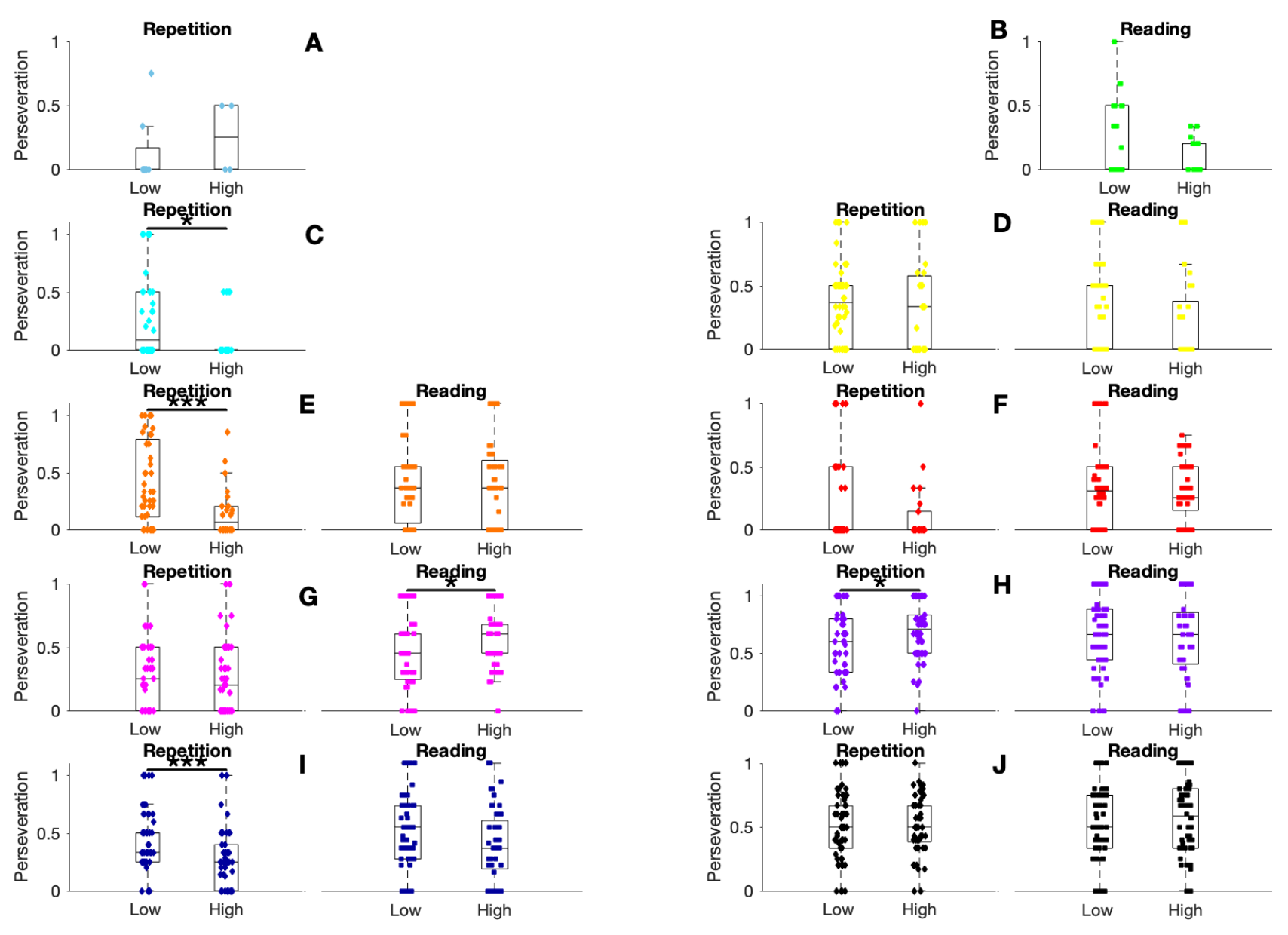

Figure 0.8: Intrusion-perseveration scores and distributions for nonword errors produced by each participant in the high and low availability conditions in repetition and reading. Stars indicate significance levels: $p \leq .05^{*}, p \leq .01^{* *}, p \leq .001^{* * *}$. 


\subsubsection{Summarising the lexicality effect}

The difference in participant performance between the low and high availability conditions was calculated for each of the three Jargon measures - number of nonwords, phonological accuracy of nonwords (POI) and phoneme perseveration within nonwords (intrusion-perseveration probability; IPS). These difference statistics, which were calculated for repetition and reading separately, were used to derive a $Z$ score for each participant. By this approach, the $Z$ score represents the degree of behavioural difference between the low and high lexical availability conditions relative to the rest of the group and is used to identify participants who exhibited the strongest effects of the lexicality manipulation. The plots represent the distribution of difference statistics across the group and demonstrate that participants with moderate Jargon impairments (C, D, and E) exhibited the greatest and most consistent effects of the lexical manipulation. The $Z$ score distributions were more variable across the reading aloud measures, with lexicality effects for phonological accuracy clustering close to zero for everyone except participant $G$, who exhibits a significant reverse frequency effect (see Figure 0.9).

To identify whether production task influenced the degree of lexicality effects, the difference statistic for each production measure for each participant was entered into a Wilcoxon signed rank test. One statistical test was carried out for each of the production measures. Results demonstrated that lexicality effects were not significantly different across repetition and reading for number of nonwords $(Z=-1.680, p=.093)$, phonological accuracy $(Z=-.560, p=.575)$ or for the intrusion-perseveration score $(Z=$ $-1.352, p=.176)$. 

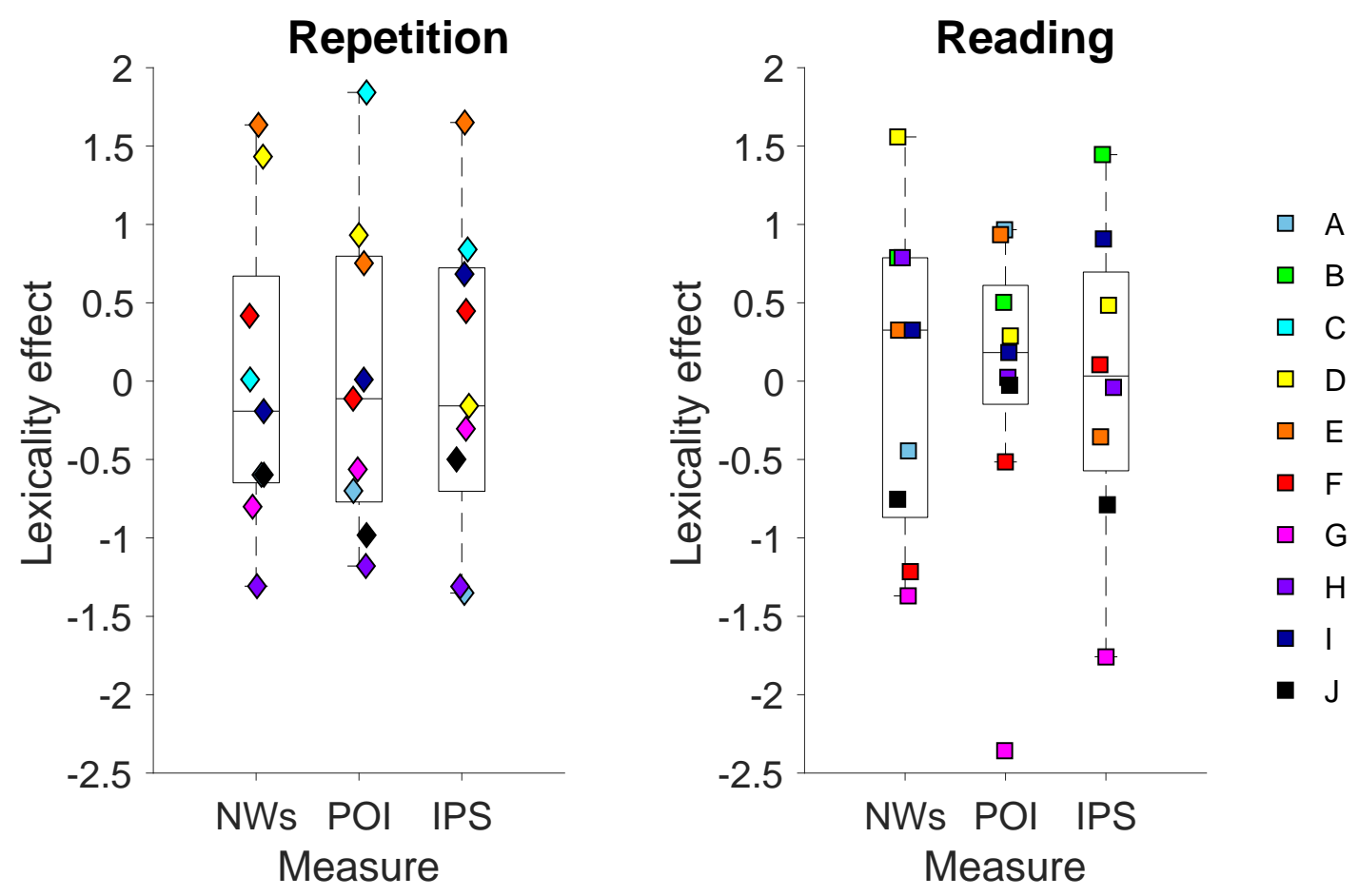

Figure 0.9: Lexical effect observed for each participant across the three different production measures in repetition and reading. $N W s=$ nonwords, $P O I=$ Phonological Overlap Index, IPS =Intrusion Perseveration Score. 


\subsection{Discussion}

This study examined whether lexical availability impacted on phonological production in Jargon aphasia. To test this, word lists of either high availability lexical items (high frequency, familiarity, imageability and concreteness) or low availability lexical items (low frequency, familiarity, imageability and concreteness) were presented for production in tasks of single word repetition and reading aloud. Crucially, the phonological processing demands of these word lists were carefully matched to ensure that lexical availability was the psycholinguistic variable under scrutiny. Jargon production was measured for quantity (number of nonwords) and quality (phonological accuracy and phoneme perseveration within nonwords). Results demonstrated that lexical availability impacts the amount of Jargon produced in that, at the group level, significantly more nonwords were produced when target words had lower lexical availability. When analysing the phonological accuracy and phoneme perseveration within nonwords, no effects of lexical availability were observed. These group level results suggest that lexical availability has a somewhat binary effect on Jargon nonword production. When lexical availability was greater, significantly fewer nonwords were observed, suggesting more successful constraint from lexical processing in minimising nonword production. However, when analysing the quality of nonword errors, lexical availability failed to influence the phonological accuracy and perseveration. This indicates that the phonological processing underpinning nonword production does not benefit from more readily available lexical information and implies that alternative processing routes, i.e. nonlexical avenues are more influential in nonword production, during reading and repetition.

The case series analyses revealed a more nuanced pattern, with a subset of participants producing fewer nonwords (participants D, E, F and I), greater phonological accuracy within nonwords (participants $C$ and D) and less phoneme perseveration (participants C, E and I) when repeating the highly available words. These results suggest that phonological processing in a portion of individuals with Jargon aphasia is influenced by lexical factors. Since the lesion and neuropsychological profile associated with Jargon aphasia indicates severe and consistent phonological processing impairment alongside variable impairment in lexical-semantic processing (Robson et al., 2017), it is reasonable to expect that individuals with greater capacity to process lexical-semantic 
information would demonstrate greater effects of lexicality, adhering to trends exhibited by neurologically healthy controls and patient groups with preserved lexicalsemantic processing (Jefferies et al., 2006; Martin \& Saffran, 1997). In the current study all participants displayed a degree of semantic impairment (see Table 2); however, no relationship was observed between the degree of semantic impairment and lexical effect size, and the subset of participants who exhibited lexical effects (C, D, E) mostly displayed poor lexical-semantic abilities. In addition, there was no relationship between the number of nonwords produced (Jargon severity) and nonverbal-semantic abilities (Camel \& Cactus Test, $\mathrm{r}=0.12, p=.737$ ) or lexical-semantic abilities (96 synonym judgement, $r=0.313, p=.377$ ), indicating a lower, non-systematic influence of lexical-semantic processing on Jargon production. Instead, Jargon severity was linearly related to phonological processing abilities (phoneme discrimination, $\mathrm{r}=-0.73, p=.016$; rhyme judgement $\mathrm{r}=-0.66, p=.037$ ) consistent with the hypothesis that phonological processes underpin Jargon production. Analysis of the phonological accuracy and perseveration measures of production quality further support this finding, as significant linear relationships were observed between the POI metric and phonological abilities (Rhyme judgement, $r=.672, p=0.33$ and Phoneme discrimination $r=-.693, p=.026$ ). No statistical relationship was observed between production quality metrics and semantic abilities (POI: .218 $<r<.426, p>.219$; Intrusion-Perseveration Score: $(-.215>$ $r>-.446, p>.196)$. It appears that the individuals who displayed lexical influences on phonological production were those with moderate degrees of Jargon severity and phonological processing ability. It is interpreted that lexical effects do not emerge in participants with mild (participants A and B) or severe (participants F, G, H and J) Jargon because the extent of the phonological impairment masks the lexical effects. By this interpretation, when phonological processing is better preserved, resulting in mild Jargon aphasia, there is sufficiently specified (although not entirely accurate) phonological activity and the magnitude of the lexical manipulation is insufficient to produce a measurable influence on phonological processing. At the opposing end, in severe Jargon where the phonological processing is significantly impaired, lexical processes are equally insufficient to overcome the impairments within the phonological system (Kohn et al., 1996). The degree of phonological impairment associated with moderate Jargon production, as observed in participants $C, D$, and E, is optimum for lexical effects to emerge. Having said this, participant I also demonstrates lexical effects, 
despite presenting with severe phonological processing impairment (see Table 2). The lexical effects exhibited by participant I may be explained by the strong dissociation between his lexical-semantic abilities (relatively preserved) and phonological abilities (severely impaired), suggesting that lexical information can impact severely impaired phonological processing if the former is particularly strong. Taken together, current results suggest that lexical effects may be generated by an interaction between lexicalsemantic and phonological processes; with lexical effects depending on the severity of phonological and semantic impairments and implying that people with stronger semantic ability capitalise on this to facilitate phonological production. These results imply that people with moderate Jargon aphasia may be more able to communicate when conversation focuses on highly frequent and familiar topics, and further work focusing on this pattern in Jargon and phonological forms of aphasia is required to better understand the nature and clinical implications of this interaction.

Within participant effects demonstrate a more complex pattern, as lexical effects differed by behavioural measure. For example, Participants I and E deviate from the group pattern in that their perseveration was impacted by lexical availability alongside the number of nonwords, but the phonological accuracy of nonwords (POI) was unaffected. In contrast, participant D displays the opposite pattern, whereby the nonword POI but not the degree of perseveration was affected by lexical availability. These patterns are unexpected in that perseverative and nonword errors are hypothesised to arise from the same mechanism; deficient target activation (Hirsh, 1998; Martin \& Dell, 2007). By this account, perseveration happens when phonological segments from the target word are weakly activated, creating greater opportunity for units with residual activation to compete and intrude and, therefore, higher perseveration should coincide with lower POI scores. However, the dissociative results from the current study indicate that the mechanisms underpinning perseverative and nonword errors are more complex. One explanation of the perseveration-POI dissociation is that the nature of the phonological impairment may differ between individuals. Kohn et al. (1996) suggest that phonological impairments in Jargon aphasia can be due to lost phonological representations or reduced access to phonological representations. Where Jargon production is underpinned by impaired access to existing representations phonological encoding can comprise segments from multiple 
non-target representations which are neighbouring or associated with the target. Those with lost phonological representations have less or no opportunity to make use of neighbouring representations resulting in greater reliance on previously used phonology and increased perseveration. Increasing the amount of activity in the phonological system, e.g. in the high lexical availability condition, could either support phonological representation access resulting in increased POI, or could bias activation away from previously active phonology resulting in lower perseveration, thus accounting for why lexical effects were observed in only one outcome measure. However, the access vs. loss hypothesis cannot account for the full pattern of data uncovered by the current study, in particular that reverse lexical availability effects were also observed.

Participants G and H displayed greater perseveration in the high lexical availability condition in reading and repetition, respectively. One possible explanation is that impaired inhibition is a further factor in the perseveration impairment displayed by these participants (Fischer-Baum \& Rapp, 2012) and that this mechanism interacts with greater activity in the high lexical availability condition. Spreading activation accounts suggest that higher frequency words produce richer activity patterns than lower frequency words due to their diverse usage (Bose, van Lieshout, \& Squares, 2007; Dell et al., 1997; Hoffman, Jefferies \& Lambon Ralph, 2011; Marshall, Pring, Chiat \& Robson, 2001), which may be associated with greater inhibitory demands. Marshall, Pring, Chiat and Robson (2001) use this account to explain the reverse frequency effect observed in their participant JP, who produced low frequency words more accurately than high frequency words. The authors suggest that high frequency words are associated with multiple semantic neighbours, which, by the spreading activation account, may result in excessive activation spreading and more extensive phonological activation. Low frequency words are associated with fewer semantic neighbours and therefore generate a more refined pattern of phonological activation. By this account, higher frequency items would elicit greater phonological activation and increase inhibitory demands, eliciting greater perseveration for people with inhibitory deficits.

A secondary hypothesis in the current study was that lexical effects would be enhanced in reading aloud in comparison to auditory repetition. This hypothesis was motivated 
by the lesion profile associated with Jargon aphasia which commonly involves the left supramarginal gyrus and superior temporal gyrus which are associated with auditoryphonological processing (Buchsbaum et al., 2011; Buchsbaum, Hickok \& Humphries, 2001). In repetition, lexical information is accessed via auditory input phonology, whereas word reading is initiated by visual processing. In Jargon aphasia, posterior regions associated with visual processing typically remain intact and functional, meaning access to lexical information can proceed more accurately (Robson et al., 2012). This pattern explains why comprehension of written material is privileged over comprehension of spoken material (see Table 1). Furthermore, a study by Nozari and Dell (2013) indicated that people with aphasia have preferences for lexical or nonlexical processing dependent on their lexical-semantic comprehension abilities; greater lexical access and comprehension ability is associated with greater weight on lexical processing, whereas more severely disrupted lexical processing capacity increases the likelihood that nonlexical processing will be utilised. Taken together, this suggests that lexical processing should be enhanced in word reading and therefore lexical effects should be exaggerated in this task. However, the case study patterns in the current group revealed the opposite effect; lexical effects were observed more so in word repetition (see Figures 3, 5 and 6). This unexpected effect can be attributed to the different transience of written and spoken stimuli in the reading and repetition tasks. Repetition involves presentation of auditory material that is highly transient, whereas reading involves the presentation of static written material which, in the current study, was present on the screen until the participant had completed their response. This inherent difference in stimuli is likely to encourage differential processing in the different tasks, with reading encouraging focus on nonlexical material since letters remain available throughout production processing, whereas repetition minimises this approach to processing since phonological material is highly transient. Therefore, repetition appears to increase use of lexical route processing as it revealed more effects of the lexical availability manipulation in the current study.

In addition to the greater lexical effects, repetition also demonstrated greater accuracy compared to reading, in participants C, F and G (see Figures 5 and 7). Participants C and G displayed a visual processing impairment as measured by the VOSP (Table 2) and participants $\mathrm{F}$ and $\mathrm{G}$ displayed lesion involvement of middle to posterior inferior 
temporal regions, therefore indicating direct damage to visual components of the reading network in these participants (Cohen \& Dehaene, 2004; Cohen, Dehaene, Vinckier, Jobert, Montavont, 2008; Richardson, Seghier, Leff, Thomas, \& Price, 2011). However, participants A and E also displayed inferior posterior temporal lobe involvement without a disproportionate reading impairment, emphasising the need for in-depth explorations of structural and functional alterations to help explain the dissociative patterns found in this and other studies of Jargon aphasia (e.g. Moses et al., 2004; Olson et al., 2015).

\section{Conclusion}

This study found that lexical information does not consistently influence phonological production in a group of people with Jargon aphasia. Instead, phonological accuracy in single word production is only consistently influenced by lexical information when phonological processing ability is moderately impaired. For people with more severe Jargon impairments, maximal amounts of lexical information do not consistently enhance phonological production; however, lexical effects were observed in one participant who displayed preserved semantic abilities, suggesting that lexical effects were dependent upon both lexical-semantic and phonological processing impairments and that lexical processing is utilised in Jargon repetition. Reading aloud demonstrated little evidence of lexical variables, suggesting that people with Jargon do not utilise their lexical processing route to facilitate and support phonological encoding, instead displaying a maladaptive strategy of focusing on phonological material to achieve production. 


\section{References}

Ackerman, T., \& Ellis, A. W. (2007). Case study: Where do aphasic perseverations come from? Aphasiology, 21(10-11), 1018-1038. doi: 10.1080/02687030701198361

Adlam, A. L., Patterson, K., Bozeat, S., \& Hodges, J. R. (2010). The Cambridge Semantic Memory Test Battery: detection of semantic deficits in semantic dementia and Alzheimer's disease. Neurocase, 16(3), 193-207. doi: $10.1080 / 13554790903405693$

Alajouanine, T. (1956). Verbal realisation in aphasia. Brain, 79, 1-28.

Baars, B. J., Motley, M. T., \& MacKay, D. G. (1975) Output editing for lexical status in artificially elicited slips of the tongue. Journal of Verbal Learning and Behaviour, 14, 382-391.

Balota, D., Yap, M., J., Hutchinson, K. A., Cortese, M. J., Kessler, B., Loftis, B., Neely., J. H., Nelson, D. L., Simpson, G. B., \& Treiman, R. (2007). Behavior Research Methods, 39(3), 445-459. https://doi.org/10.3758/BF03193014.

Baron, J., \& Strawson, C. (1976). Use of orthographic and word-specific knowledge in reading words aloud. Journal of Experimental Psychology: Human Perception and Performance, 2(3), 386-393. doi: 10.1037/0096-1523.2.3.386

Bayles, K. A., Tomoeda, C. K., Kaszniak, A. W., Stern, L. Z., \& Eagans, K. K. (1985). Verbal perseveration of dementia patients. Brain and Language, 25(1), 102-116.

Binder, J. R. (2017). Current Controversies on Wernicke's Area and its Role in Language. Curr Neurol Neurosci Rep, 17(8), 58. doi: 10.1007/s11910-017-0764-8

Blumstein, S. E., Cooper, W. E., Goodglass, H., Statlender, S., \& Gottlieb, J. (1980). Production deficits in aphasia: A voice-onset time analysis. Brain and Language, 9(2), 153-170. doi: https://doi.org/10.1016/0093-934X(80)90137-6

Bose, A., van Lieshout, P., \& Squares, P. A. (2007). Word frequency and bigram frequency effects on linguistic processing and speech motor performance in individuals with aphasia and normal speakers. Journal of Neurolinguistics, 20(1), 65-88, doi.org/10.1016/j.jneuroling.2006.05.001

Brown, J. W. (1981). Chapter 1 - Introduction Jargonaphasia (pp. 1-8): New York:Academic Press.

Brown, J. W. (1981). Chapter 9 - Case Reports of Semantic Jargon (pp. 169-176): New York:Academic Press. 
Buchsbaum, B. R., Baldo, J., Okada, K., Berman, K. F., Dronkers, N., D'Esposito, M., \& Hickok, G. (2011). Conduction aphasia, sensory-motor integration, and phonological short-term memory - an aggregate analysis of lesion and fMRI data. Brain and Language, 119(3), 119-128. doi: 10.1016/j.bandl.2010.12.001

Buchsbaum,B. R., Hickok, G., \& Humphries, C. (2001). Role of left posterior superior temporal gyrus in phonological processing for speech perception and production. Cognitive Science, 25, 663-678. https://doi.org/10.1207/s15516709cog2505_2

Buckingham, H. W. (1977). The Conduction Theory and Neologistic Jargon. Language and Speech, 20(2), 174-184. https://doi.org/10.1177/002383097702000209

Buckingham, H. W. (1990). Abstruse neologisms, retrieval deficits and the random generator. J Neurolinguistics, 5(2-3), 215-235. doi: http://dx.doi.org/10.1016/0911-6044(90)90012-N

Buckingham, H. W., \& Buckingham, S. S. (2011). Is recurrent perseveration a product of deafferented functional systems with otherwise normal post-activation decay rates? Clin Linguist Phon, 25(11-12), 1066-1073. doi: 10.3109/02699206.2011.616982

Buckingham Jr, H. W., \& Kertesz, A. (1974). A linguistic analysis of fluent aphasia. Brain and Language, 1(1), 43-61. doi: http://dx.doi.org.idpproxy.reading.ac.uk/10.1016/0093-934X(74)90025-X

Cohen, L., \& Dehaene, S. (2004). Specialization within the ventral stream: the case for the visual word form area. Neuroimage, 22(1), 466-476, https://doi.org/10.1016/j.neuroimage.2003.12.049

Cohen, L., \& Dehaene, S. (1998). Competition between past and present. Assessment and interpretation of verbal perseverations. Brain, 121(9), 1641-1659.

Cohen, L., Dehaene, S., Vinckier, F., Jobert, A., \& Montavont, A. (2008). Reading normal and degraded words: Contribution of the dorsal and ventral visual pathways. Neuroimage, 40, 353:366

Coltheart, M. (1981). The MRC psycholinguistic database. The Quarterly Journal of Experimental Psychology Section A, 33(4), 497-505. doi: $10.1080 / 14640748108400805$ 
Coltheart, M., Curtis, B., Atkins, P., \& Haller, M. (1993). Models of reading aloud: Dualroute and parallel-distributed- processing approaches. Psychol Rev, 100(4), 589608.

Coltheart, M., Rastle, K., Perry, C., Langdon, R., \& Ziegler, J. (2001). DRC: a dual route cascaded model of visual word recognition and reading aloud. Psychol Rev, 108(1), 204-256.

Corbett, F., Jefferies, E., \& Lambon Ralph, M. A. (2008). The use of cueing to alleviate recurrent verbal perseverations: Evidence from transcortical sensory aphasia. Aphasiology, 22(4), 363-382. doi: 10.1080/02687030701415245

Crisp, J., \& Lambon Ralph, M. A. (2006). Unlocking the nature of the phonological-deep dyslexia continuum: the keys to reading aloud are in phonology and semantics. $J$ Cogn Neurosci, 18(3), 348-362. doi: 10.1162/089892906775990543

Dell, G. S., Martin, N., \& Schwartz, M. F. (2007). A Case-Series Test of the Interactive Twostep Model of Lexical Access: Predicting Word Repetition from Picture Naming. Journal of Memory and Language, 56(4), 490-520. doi: 10.1016/j.jml.2006.05.007

Dell, G. S., \& Reich, P. A. (1981) Stages in sentence production: An analysis of speech error data. Journal of Verbal Learning and Verbal Behaviour, 20, 611-629.

Dell, G. S., Schwartz, M. F., Martin, N., Saffran, E. M., \& Gagnon, D. A. (1997). Lexical access in aphasic and nonaphasic speakers. Psychol Rev, 104(4), 801-838.

Demeyere N, Riddoch MJ, Slavkova ED, Bickerton W-L, \& Humphreys GW. (2015). The Oxford Cognitive Screen (OCS): Validation of a stroke-specific short cognitive screening tool. Psychological Assessment, 27(3), 883-894.

Eaton, E., Marshall, J. \& Pring, T. (2011). Mechanisms of change in the evolution of jargon aphasia. Aphasiology, 25(12), pp. 1543-1561. doi: $10.1080 / 02687038.2011 .624584$

Fischer-Baum, S., \& Rapp, B. (2012). Underlying cause(s) of letter perseveration errors. Neuropsychologia, 50(2), 305-318. doi: http://dx.doi.org/10.1016/j.neuropsychologia.2011.12.001

Foygel, D., \& Dell, G. S. (2000). Models of Impaired Lexical Access in Speech Production. Journal of Memory and Language, 43(2), 182-216. doi: https://doi.org/10.1006/jmla.2000.2716 
Frankel, T., Penn, C., \& Ormond-Brown, D. (2007). Executive dysfunction as an explanatory basis for conversation symptoms of aphasia: A pilot study. Aphasiology, 21(6-8), 814-828.

Gerhand, S., \& Barry, C. (1998). Word frequency effects in oral reading are not merely age-of-acquisition effects in disguise. Journal of Experimental Psychology: Learning, Memory, and Cognition, 24(2), 267-283. doi: 10.1037/02787393.24.2.267

Godbold, C. (2016). Non-word errors in jargon aphasia : exploring the underlying mechanisms. Thesis (PhD.) - University of Reading, School of Psychology \& Clinical Language Sciences.

Goodglass, H., Kaplan, E., \& Barresi, B. (2001). The Boston Diagnostic Aphasia Examination. Philadelphia, PA: Lippincott.

Gotts, S. J., della Rocchetta, A. I., \& Cipolotti, L. (2002). Mechanisms underlying perseveration in aphasia: evidence from a single case study. Neuropsychologia, 40(12), 1930-1947. doi: Pii S0028-3932(02)00067-2Doi 10.1016/S00283932(02)00067-2

Grainger, J., \& Segui, J. (1990). Neighborhood frequency effects in visual word recognition: A comparison of lexical decision and masked identification latencies. Perception \& Psychophysics, 47(2), 191-198. doi: 10.3758/BF03205983

Halpern, H. (1965). Effect of Stimulus Variables on Verbal Perseveration of Dysphasic Subjects. Perceptual and Motor Skills, 20(2), 421-429. doi: 10.2466/pms.1965.20.2.421

Hanley, J. R., \& Kay, J. R(1997). An Effect of Imageability on the Production of Phonological Errors in Auditory Repetition. Cognitive Neuropsychology, 14(8), 1065-1084. doi: 10.1080/026432997381277

Hanley, J. R., Kay, J., \& Edwards, M. (2002). Imageability effects, phonological errors, and the relationship between auditory repetition and picture naming: Implications for models of auditory repetition. Cognitive Neuropsychology, 19(3), 193-206. doi: $10.1080 / 02643290143000132$

Hillis, A. E. (2007). Aphasia. Neurology, 69(2), 200.

Hillis, A. E., Boatman, D., Hart, J., \& Gordon, B. (1999). Making sense out of jargon. Neurology, 53(8), 1813. 
Hirsh, K. W. (1998). Perseveration and Activation in Aphasic Speech Production. Cognitive Neuropsychology, 15(4), 377-388. doi: 10.1080/026432998381140 Hoffman, P., Jefferies, B., \& Lambon Ralph, M. A. (2011). Remembering 'zeal' but not 'thing': Reverse frequency effects as a consequence of deregulated semantic processing. Neuropsychologia, 49(3), 580-584. doi.org/10.1016/j.neuropsychologia.2010.12.036

Hulme, C., Roodenrys, S., Schweickert, R., Brown, G. D., Martin, M., \& Stuart, G. (1997). Word-frequency effects on short-term memory tasks: evidence for a redintegration process in immediate serial recall. J Exp Psychol Learn Mem Cogn, 23(5), 1217-1232.

Jefferies, E., Crisp, J., \& Ralph, M. A. L. (2006). The impact of phonological or semantic impairment on delayed auditory repetition: Evidence from stroke aphasia and semantic dementia. Aphasiology, 20(9), 963-992. doi: $10.1080 / 02687030600739398$

Jefferies, E., Patterson, K., Jones, R. W., \& Lambon Ralph, M. A. (2009). Comprehension of concrete and abstract words in semantic dementia. Neuropsychology, 23(4), 492499. doi: $10.1037 / \mathrm{a} 0015452$

Kay, J., Lesser, R., \& Coltheart, M. (1996). Psycholinguistic assessments of language processing in aphasia (PALPA): An introduction. Aphasiology, 10(2), 159-180. doi: $10.1080 / 02687039608248403$

Kertesz, A. (1981). Chapter 4 - The Anatomy of Jargon A2 - BROWN, JASON W Jargonaphasia (pp. 63-112): Academic Press.

Kertesz, A., \& Benson, D. F. (1970). Neologistic Jargon: A Clinicopathological Study. Cortex, 6(4), 362-386. doi: http://dx.doi.org/10.1016/S0010-9452(70)80002-8

Kinsbourne, M., \& Warrington, E. (1963). Jargon aphasia. Neuropsychologia, 1(1), 27-37. https://doi.org/10.1016/0028-3932(63)90010-1

Kittredge, A. K., Dell, G. S., Verkuilen, J., \& Schwartz, M. F. (2008). Where is the effect of frequency in word production? Insights from aphasic picture-naming errors. Cognitive Neuropsychology, 25(4), 463-492. doi: 10.1080/02643290701674851

Kohn, S. E., Smith, K. L., \& Alexander, M. P. (1996). Differential recovery from impairment to the phonological lexicon. Brain and Language, 52(1), 129-149. doi: 10.1006/brln.1996.0007 
Laszlo, S., \& Federmeier, K. D. (2007). Better the DVL You Know: Acronyms Reveal the Contribution of Familiarity to Single-Word Reading. Psychological Science, 18(2), 122-126. doi: 10.1111/j.1467-9280.2007.01859.x

Marshall, J. (2006). Jargon aphasia: What have we learned? Aphasiology, 20(5), 387-410. doi: 10.1080/02687030500489946

Marshall, J., Chiat, S., Robson, J., \& Pring, T. (1996). Calling a salad a federation: an investigation of semantic Jargon. Paper 2, Verbs. Journal of Neurolinguistics, 9, 251-260.

Marshall, J., Pring, T., Chiat, S., \& Robson, J. (2001). When Ottoman is Easier than Chair: An Inverse Frequency Effect in Jargon Aphasia. Cortex, 37(1), 33-53. doi.org/10.1016/S0010-9452(08)70556-2

Marshall, J., Robson, J., Pring, T., \& Chiat, S. (1998). Why does monitoring fail in Jargon aphasia? Comprehension, judgement and therapy evidence. Brain and Language, 1(1), 79-107. https://doi.org/10.1006/brln.1997.1936

Martin, N., \& Dell, G. S. (2007). Common mechanisms underlying perseverative and nonperseverative sound and word substitutions. Aphasiology, 21(10-11), 1002-1017. doi: $10.1080 / 02687030701198346$

Martin, N., \& Saffran, E. M. (1997). Language and auditory-verbal short-term memory impairments: Evidence for common underlying processes. Cognitive Neuropsychology, 14(5), 641-682. doi: 10.1080/026432997381402

McCarthy, R., \& Warrington, E. K. (1984). A two-route model of speech production. Evidence from aphasia. Brain, 107 ( Pt 2), 463-485.

McCloskey, M., Macaruso, P., \& Rapp, B. (2006). Grapheme-to-lexeme feedback in the spelling system: Evidence from a dysgraphic patient. Cognitive Neuropsychology, 23(2), 278-307. doi: 10.1080/02643290442000518

Mesgarani N., Cheung, C., Johnson, K., \& Chang, E. F. (2014). Phonetic feature encoding in human superior temporal gyrus. Science. 343(6174):1006-10. doi: 10.1126/science.1245994.

Monsell, S., Doyle, M. C., \& Haggard, P. N. (1989). Effects of frequency on visual word recognition tasks: where are they? J Exp Psychol Gen, 118(1), 43-71.

Moses, M. S., Nickels, L. A., \& Sheard, C. (2004). Disentangling the web: Neologistic perseverative errors in jargon aphasia. Neurocase, 10(6), 452-461. doi: $10.1080 / 13554790490894057$ 
Moses, M. S., Sheard, C., \& Nickels, L. A. (2007). Insights into recurrent perseveration errors in aphasia: A case series approach. Aphasiology, 21:10-11, 975-1001, DOI: 10.1080/02687030701198312.

Nickels, L., \& Howard, D. (2004). Dissociating Effects of Number of Phonemes, Number of Syllables, and Syllabic Complexity on Word Production in Aphasia: It's the Number of Phonemes that Counts. Cognitive Neuropsychology, 21(1), 57-78.

Nozari, N., \& Dell, G. S. (2013). How damaged brains repeat words: A computational approach. Brain and Language, 126(3), 327-337. doi: https://doi.org/10.1016/j.bandl.2013.07.005

Nozari, N., Kittredge, A. K., Dell, G. S., \& Schwartz, M. F. (2010). Naming and repetition in aphasia: Steps, routes, and frequency effects. Journal of Memory and Language, 63(4), 541-559. doi: http://dx.doi.org/10.1016/j.jml.2010.08.001

O'Connell, P. F. (1981). Neologistic jargon aphasia: A case report. Brain and Language, 12(2), 292-302. doi: https://doi.org/10.1016/0093-934X(81)90020-1

Olson, A., Halloran, E., \& Romani, C. (2015). Target/error overlap in jargonaphasia: The case for a one-source model, lexical and non-lexical summation, and the special status of correct responses. Cortex, 73, 158-179. doi: http://dx.doi.org/10.1016/j.cortex.2015.06.028

Olson, A. C., Romani, C., \& Halloran, L. (2007). Localizing the deficit in a case of jargonaphasia. Cognitive Neuropsychology, 24(2), 211-238. doi: $10.1080 / 02643290601137017$

Papagno, C., \& Basso, A. (1996). Perseveration in two aphasic patients. Cortex, 32(1), $67-$ 82.

Patterson, K., Graham, N., \& Hodges, J. R. (1994). The impact of semantic memory loss on phonological representations. J Cogn Neurosci, 6(1), 57-69. doi: 10.1162/jocn.1994.6.1.57

Pekkala, S., Albert, M. L., Spiro Iii, A., \& Erkinjuntti, T. (2008). Perseveration in Alzheimer's disease. Dementia and geriatric cognitive disorders, 25(2), 109-114.

Pilkington, E., Keidel, J., Kendrick, L. T., Saddy, J. D., Sage, K., \& Robson, H. (2017). Sources of Phoneme Errors in Repetition: Perseverative, Neologistic, and Lesion Patterns in Jargon Aphasia. Frontiers in Human Neuroscience, 11(225). doi: 10.3389/fnhum.2017.00225 
Pilkington, E., Sage, K., Saddy, D. and Robson, H. (2019) What can repetition, reading and naming tell us about Jargon Aphasia? Journal of Neurolinguistics, 49. pp. 45-56. ISSN 0911-6044 doi: https://doi.org/10.1016/j.jneuroling.2018.08.003

Plaut, D. C., \& Kello, C. T. (1999). The emergence of phonology from the interplay of speech comprehension and production: A distributed connectionist approach The emergence of language. (pp. 381-415). Mahwah, NJ, US: Lawrence Erlbaum Associates Publishers.

Purcell, R., Lambon-Ralph, M., \& Sage, K. (2018). Investigating the language, cognition and self-monitoring abilities of speakers with jargon output. Aphasiology, DOI: $10.1080 / 02687038.2018 .1532070$

Rayner, K., \& Duffy, S. A. (1986). Lexical complexity and fixation times in reading: Effects of word frequency, verb complexity, and lexical ambiguity. Memory \& Cognition, 14(3), 191-201. doi: 10.3758/BF03197692

Richardson, F. M., Seghier, M. L., Leff, A. P., Thomas, M. S. C., \& Price, C. (2011). Multiple Routes from Occipital to Temporal Cortices during Reading. Journal of Neuroscience, 31(22) 8239:8247. DOI: https://doi.org/10.1523/JNEUROSCI.6519-10.2011

Robin, D. A., \& Schienberg, S. (1990). Subcortical lesions and aphasia. Journal of Speech and Hearing Disorders, 55(1), 90-100.

Robinson, G. A., Butterworth, B., \& Cipolotti, L. (2015). “My Mind Is Doing It All”: No "Brake" to Stop Speech Generation in Jargon Aphasia. Cognitive and Behavioral Neurology, 28(4), 229-241.

Robson, H., Grube, M., Lambon Ralph, M. A., Griffiths, T. D., \& Sage, K. (2013). Fundamental deficits of auditory perception in Wernicke's aphasia. Cortex, 49(7), 1808-1822. doi: 10.1016/j.cortex.2012.11.012

Robson, H., Pilkington, E., Evans, L., DeLuca, V. and Keidel, J. (2017) Phonological and semantic processing during comprehension in Wernicke's aphasia: a N400 and Phonological Mapping Negativity study. Neuropsychologia, 100. pp. 144-154. ISSN 0028-3932 doi: https://doi.org/10.1016/j.neuropsychologia.2017.04.012

Robson, H., Sage, K. and Lambon Ralph, M. A. (2012) Wernicke's aphasia reflects a combination of acoustic-phonological and semantic control deficits: A case-series comparison of Wernicke's aphasia, semantic dementia and semantic aphasia. 
Neuropsychologia, 50 (2). pp. 266-275. ISSN 0028-3932 doi:

https://doi.org/10.1016/j.neuropsychologia.2011.11.021

Robson, H., Specht, K., Beaumont, H., Parkes, L. M., Sage, K., Lambon Ralph, M. A., \& Zahn, R. (2017). Arterial spin labelling shows functional depression of non-lesion tissue in chronic Wernicke's aphasia. Cortex, 92: 249-260.

Robson, J., Pring, T., Marshall, J., \& Chiat, S. (2003). Phoneme frequency effects in jargon aphasia: a phonological investigation of nonword errors. Brain and Language, 85(1), 109-124.

Romani, C., Galluzzi, C., \& Olson, A. (2011). Phonological-lexical activation: A lexical component or an output buffer? Evidence from aphasic errors. Cortex, 47(2), 217-235. doi: https://doi.org/10.1016/j.cortex.2009.11.004

Rorden, C, \& Brett, M. (2000) Stereotaxic display of brain lesions. Behavioural Neurology 12(4), 191-200.

Sampson, M., \& Faroqi-Shah, Y. (2011). Investigation of self-monitoring in fluent aphasia with jargon. Aphasiology. 25:4, 505-528, doi: 10.1080/02687038.2010.523471

Sandson, J., \& Albert, M. L. (1984). Varieties of perseveration. Neuropsychologia, 22(6), 715-732.

Sandson, J., \& Albert, M. L. (1987). Perseveration in behavioral neurology. Neurology, 37(11), 1736-1736.

Santo Pietro, M. J., \& Rigrodsky, S. (1986). Patterns of oral-verbal perseveration in adult aphasics. Brain and Language, 29(1), 1-17.

Schwartz, M. F., Saffran, E. M., Bloch, D. E., and Dell, G. S. (1994). Disordered Speech Production in Aphasic and Normal Speakers. Brain and Language, 47, 52-88.

Schwartz, M. F., Wilshire, C. E., Gagnon, D. A., \& Polansky, M. (2004). Origins of nonword phonological errors in aphasic picture naming. Cognitive Neuropsychology, 21(24), 159-186. https://doi.org/10.1080/02643290342000519

Strain, E., Patterson, K., \& Seidenberg, M. S. (1995). Semantic effects in single-word naming. Journal of Experimental Psychology: Learning, Memory, and Cognition, 21(5), 1140-1154. doi: 10.1037/0278-7393.21.5.1140

Strain, E., Patterson, K., \& Seidenberg, M. S. (2002). Theories of word naming interact with spelling--sound consistency. Journal of Experimental Psychology: Learning, Memory, and Cognition, 28(1), 207-214. doi: 10.1037/0278-7393.28.1.207 
Vitevitch, M.S. \& Luce, P.A. (2004). A Web-based interface to calculate phonotactic probability for words and nonwords in English. Behavior Research Methods, Instruments, \& Computers. 36: 481. https://doi.org/10.3758/BF03195594

Wang, J., Mathalon, D. J., Roach, B. J., Reilly, J., Keedy, S. K., Sweeny, J. K., \& Ford, J. M. (2014). Action planning and predictive coding when speaking. Neuroimage, 91, 91-98. Doi: https://doi.org/10.1016/j.neuroimage.2014.01.003

Warrington, E. K., \& James, M. (1991). Visual Object and Space Perception Battery (VOSP). Bury St. Edmunds (UK): Thames Valley Test Company

Weekes, B. S. (1997). Differential Effects of Number of Letters on Word and Nonword Naming Latency. The Quarterly Journal of Experimental Psychology Section A, 50(2), 439-456. doi: 10.1080/713755710

Yamadori, A. (1981). Verbal perseveration in aphasia. Neuropsychologia, 19(4), 591594. 


\section{Tables}

Table 1: Participant demographic and neurological information.

Table 2: Participant raw and percentage () scores on semantic, phonological, visual and cognitive assessments.

Table 3: Number of nonwords and Fishers $p$ test statistics for lexicality effect on number of nonwords in repetition and reading.

Table 4: Mann Whitney U test statistics for lexicality effect on POI in repetition and reading.

Table 5: Mann Whitney U test statistics for lexicality effect on intrusion-perseveration score in repetition and reading.

\section{Figures}

Figure 1: Boston Diagnostic Aphasia Profiles for Jargon aphasia participants.

Figure 2: Proportion of correct, nonword and other responses produced on single word production tasks.

Figure 3: Lesion overlay identifying common regions of damage. Colour bar indicates number of participants with lesion at each voxel $(3 \geq n \geq 8)$.

Figure 4: Number of nonwords produced on low and high availability word sets for repetition and reading. Individual markers indicate total nonwords produced by each participant. Participant colours presented in key.

Figure 5: Phonological Overlap Index (POI) distributions for low and high availability word sets in repetition and reading. Individual markers indicate participant means. Participant colours presented in key. 
Figure 6: Phonological Overlap Index scores and distributions for nonword errors produced by each participant in the high and low availability conditions in repetition and reading. Individual markers indicate POI scores obtained per nonword error. Stars indicate significance levels: $p \leq .05^{*}, p \leq .01^{* *}, p \leq .001^{* * *}$.

Figure 7: Intrusion-perseveration distributions for low and high availability word sets in repetition and reading. Individual markers indicate participant means. Participant colours presented in key.

Figure 8: Intrusion-perseveration scores and distributions for nonword errors produced by each participant in the high and low availability conditions in repetition and reading. Individual markers indicate intrusion-perseveration scores obtained per nonword error. Stars indicate significance levels: $p \leq .05^{*}, p \leq .01^{* *}, p \leq .001^{* * *}$.

Figure 9: Z scores corresponding to difference statistics calculated for production measures of nonword quantity, phonological accuracy (POI) and perseveration (IPS) between high and low lexical availability conditions for word repetition and reading. 


\section{Appendices}

\section{Appendix 1}

Target word sets

\section{Appendix 2}

Mean and standard deviation (in parentheses) statistics of psycholinguistic values for target word sets.

\section{Appendix 3}

Number of correct, nonword and other response types observed on tasks of single word repetition and reading for each participant. 


\section{Appendix 1}

Target word sets

\begin{tabular}{|c|c|c|c|}
\hline \multicolumn{2}{|c|}{ Repetition } & \multicolumn{2}{|c|}{ Reading } \\
\hline High & Low & High & Low \\
\hline apartment & abode & animal & analogy \\
\hline arm & acre & avenue & audit \\
\hline audience & ally & band & border \\
\hline bag & altitude & bridge & clash \\
\hline building & anecdote & candidate & compression \\
\hline butter & annex & cellar & crush \\
\hline camp & aurora & chain & cult \\
\hline car & beau & champion & debut \\
\hline cattle & betrayal & chapel & defence \\
\hline clay & bid & clothes & defiance \\
\hline coffee & blessing & coach & despair \\
\hline column & boast & core & dirge \\
\hline display & brawl & country & enigma \\
\hline drink & circuit & customer & flutter \\
\hline drug & continent & detective & foe \\
\hline executive & cunning & dive & fortune \\
\hline filling & curse & driver & franchise \\
\hline flash & deceit & earth & frenzy \\
\hline gallery & denial & edge & fury \\
\hline golf & dislocation & entrance & grievance \\
\hline graduate & dismissal & forest & gush \\
\hline grip & etiquette & ground & impediment \\
\hline hall & expanse & hill & incline \\
\hline professor & exterior & hotel & inhibition \\
\hline human & flyer & industry & irritation \\
\hline lift & forfeit & lunch & jerk \\
\hline liquid & fraud & market & lunge \\
\hline magazine & genius & material & margin \\
\hline metal & gore & money & misery \\
\hline monument & greed & mud & oath \\
\hline motor & gulf & muscle & omen \\
\hline music & haste & ocean & pact \\
\hline newspaper & insight & painting & peep \\
\hline novel & irony & paper & pioneer \\
\hline partner & jolt & park & precaution \\
\hline pattern & levity & penny & rebel \\
\hline planet & loyalty & picture & receipt \\
\hline pocket & maker & platform & regency \\
\hline pool & marvel & pond & retreat \\
\hline porch & mortal & quarter & rhyme \\
\hline
\end{tabular}




\begin{tabular}{llll} 
property & raid & radio & scorn \\
record & realm & rain & sedative \\
room & reprisal & register & sequel \\
sand & revenge & rifle & shrug \\
saw & rogue & salary & siege \\
shadow & saga & salt & sorrow \\
skirt & shaker & secretary & stride \\
smile & sneer & sheet & strut \\
soil & snort & shirt & tally \\
soldier & spree & silver & thaw \\
student & thinker & smoke & theft \\
sun & treaty & staff & tip \\
tape & tremor & station & torment \\
teacher & tumble & supper & trance \\
uniform & utterance & university & trim \\
valley & verity & water & tuck \\
victim & vigil & winter & turner \\
village & vow & witness & venture \\
weapon & whack & wound & watt \\
wedding & whirl & writing & wiggle \\
\hline
\end{tabular}




\section{Appendix 2}

Mean and standard deviation (in parentheses) statistics of psycholinguistic values for target word sets.

\begin{tabular}{|c|c|c|c|c|}
\hline & \multicolumn{2}{|c|}{ Repetition } & \multicolumn{2}{|c|}{ Reading } \\
\hline & High & Low & High & Low \\
\hline KF frequency & $82.82(78.53)$ & $7.60(6.74)$ & $86.33(80.04)$ & $7.62(6.60)$ \\
\hline Celex frequency & 73.947 (87.39) & $6.34(5.80)$ & $79.94(88.60)$ & $8.76(12.3)$ \\
\hline Log frequency & $1.71(0.36)$ & $0.73(0.36)$ & $1.72(0.40)$ & $0.81(0.38)$ \\
\hline Concreteness & $549.67(47.53)$ & $366.60(76.53)$ & $554.03(51.03)$ & $365.67(61.61)$ \\
\hline Familiarity & $550.83(52.83)$ & $414.08(58.47)$ & $556.97(52.45)$ & $422.88(58.8)$ \\
\hline Imageability & $561.55(42.96)$ & $408.17(61.63)$ & $563.08(48.75)$ & $408.28(65.14)$ \\
\hline Phoneme number & $4.93(1.74)$ & $4.93(1.76)$ & $5.00(1.74)$ & $4.98(1.81)$ \\
\hline Syllable number & $1.82(0.75)$ & $1.93(0.82)$ & $1.88(0.83)$ & $1.87(0.89)$ \\
\hline Letter number & $5.77(1.70)$ & $5.93(1.66)$ & $5.97(1.56)$ & $5.98(1.87)$ \\
\hline Phonological neighbourhood density & $7.5(8.79)$ & $6.13(8.62)$ & $8.18(9.78)$ & $6.2(8.27)$ \\
\hline Orthographic neighbourhood density & $3.90(5.04)$ & $2.47(3.09)$ & $3.04(4.47)$ & $2.67(3.43)$ \\
\hline Phoneme position frequency & $0.26(0.11)$ & $0.26(0.13)$ & $0.27(0.13)$ & $0.25(0.11)$ \\
\hline Biphone position frequency & $0.021(0.02)$ & $0.02(0.02)$ & $0.021(0.02)$ & $0.02(0.02)$ \\
\hline Bigram position frequency & $1685.03(893.19)$ & $1654.32(1041.67)$ & $1931.03(936.26)$ & $1645.25(1002.95)$ \\
\hline
\end{tabular}




\section{Appendix 3}

Number of correct, nonword and other responses types observed on tasks of single word repetition and reading for each participant.

\begin{tabular}{|c|c|c|c|c|c|c|c|c|c|c|c|c|c|c|c|c|c|c|c|c|c|}
\hline \multirow[b]{3}{*}{$\begin{array}{c}\text { Response } \\
\text { type }\end{array}$} & \multirow[b]{3}{*}{$\begin{array}{c}\text { Lexical } \\
\text { availability }\end{array}$} & \multicolumn{10}{|c|}{ Repetition } & \multicolumn{10}{|c|}{ Reading } \\
\hline & & \multicolumn{20}{|c|}{ Participant code } \\
\hline & & A & B & C & D & $\mathbf{E}$ & $\mathbf{F}$ & $\mathbf{G}$ & $\mathbf{H}$ & I & $\mathbf{J}$ & $\mathbf{A}$ & B & C & D & $\mathbf{E}$ & $\mathbf{F}$ & $\mathbf{G}$ & $\mathbf{H}$ & I & J \\
\hline \multirow[t]{2}{*}{ Correct } & Low & 43 & - & 2 & 3 & 0 & 17 & 3 & 0 & 0 & 0 & 57 & 27 & - & 6 & 0 & 0 & 0 & 0 & 0 & 0 \\
\hline & High & 51 & - & 9 & 26 & 3 & 22 & 11 & 0 & 0 & 0 & 58 & 39 & - & 20 & 2 & 2 & 0 & 1 & 1 & 0 \\
\hline \multirow[t]{2}{*}{ Nonword } & Low & 8 & - & 35 & 51 & 53 & 37 & 45 & 56 & 60 & 58 & 3 & 27 & - & 44 & 44 & 51 & 56 & 59 & 60 & 59 \\
\hline & High & 4 & - & 25 & 27 & 27 & 23 & 43 & 59 & 52 & 54 & 1 & 17 & - & 29 & 37 & 54 & 60 & 49 & 53 & 59 \\
\hline \multirow[t]{2}{*}{ Formal } & Low & 6 & - & 5 & 4 & 2 & 4 & 8 & 1 & 0 & 0 & 0 & 6 & - & 4 & 11 & 2 & 1 & 1 & 0 & 0 \\
\hline & High & 5 & - & 5 & 4 & 8 & 11 & 5 & 1 & 2 & 1 & 1 & 4 & - & 7 & 14 & 1 & 0 & 5 & 3 & 0 \\
\hline \multirow[t]{2}{*}{ Unrelated } & Low & 2 & - & 10 & 1 & 5 & 1 & 3 & 3 & 0 & 1 & 0 & 0 & - & 4 & 5 & 7 & 3 & 0 & 0 & 1 \\
\hline & High & 0 & - & 6 & 3 & 21 & 1 & 0 & 0 & 6 & 4 & 0 & 0 & - & 3 & 7 & 3 & 0 & 4 & 3 & 1 \\
\hline \multirow[t]{2}{*}{ Semantic } & Low & 0 & - & 0 & 0 & 0 & 0 & 0 & 0 & 0 & 0 & 0 & 0 & - & 0 & 0 & 0 & 0 & 0 & 0 & 0 \\
\hline & High & 0 & - & 0 & 0 & 1 & 1 & 0 & 0 & 0 & 0 & 0 & 0 & - & 0 & 0 & 0 & 0 & 0 & 0 & 0 \\
\hline \multirow[t]{2}{*}{ Mixed } & Low & 1 & - & 0 & 1 & 0 & 0 & 0 & 0 & 0 & 0 & 0 & 0 & - & 2 & 0 & 0 & 0 & 0 & 0 & 0 \\
\hline & High & 0 & - & 0 & 0 & 0 & 2 & 0 & 0 & 0 & 0 & 0 & 0 & - & 1 & 0 & 0 & 0 & 1 & 0 & 0 \\
\hline \multirow[t]{2}{*}{$\begin{array}{l}\text { Non- } \\
\text { response }\end{array}$} & Low & 0 & - & 8 & 0 & 0 & 1 & 1 & 0 & 0 & 1 & 0 & 0 & - & 0 & 0 & 0 & 0 & 0 & 0 & 0 \\
\hline & High & 0 & - & 15 & 0 & 0 & 0 & 1 & 0 & 0 & 1 & 0 & 0 & - & 0 & 0 & 0 & 0 & 0 & 0 & 0 \\
\hline
\end{tabular}

